\title{
La crisis algodonera en El Salvador: tendencias y perspectivas
}

\author{
Allonso Goitia
}

\section{Introducción}

La producción algodonera durante los últimos anos ha sufrido una drástica caida, la superticie culivada de algodón se redujo para la cosecha 1986/87 a 19,650 manazanas, más de 7 veces inlerior al área cultivada en 1978/79 que fue de 150.329 manzanas. Esta disminución del $87 \%$ del área cultivada entre 1978 a 1987 significó a su vez contracción de la producción de algodón rama y oro en casi la misma proporción.

El algodón representaba para la economía salvadoreña el segundo producto de exportación, "generaba alrededor del 9\% del PIB agropecuario, el $2 \%$ del PIB lotal, el $9.5 \%$ de los ingresos de divisas I pais por concepto de exportaciones, además proveia empleo alrededor de 150.000 personas en la lase agrlcola solamente. $*$ La actividad abastece de maleria prima a la industria textil nacional, la cual también tiene un impacto significativo sobre la balanza de pagos yel empleo; la semilla se procesa como maleria prima en la fabricación de acenta y se obtienen otros subproduclos para la fabricación de concentrados de alimentación animal". 1

El hecho de considerar que la actividad algodonera esta en crisis, se deriva por un lado de su persistenle tendencia a la caida del área cultivada y de su producción, asl como a los efectos negativos que liene sobre el empleo, la generación de divisas y sobre olras actividades económicas.

En esle estudio se pretende mostrar cuales son los factores o las causas que han provocado la caida en la producción algodonera y a 
través de ello demostrar la complejidad y dificultades que tiene el buscar soluciones si se pretende atacar el problema desde una visión parcial y limitada de la crisis algodonera. Se trata también de analizar las tendencias que ha presentado el mercado del algodón visto desde el lado de la oferla y la demanda a fin de evidenciar las implicaciones que tiene esta crisis, sobre las necesidades de fibra y otros insumos derivados del algodón en otras actividades económicas.

Por úllimo se trata de analizar la siluación de los productores de algodón, a través de la estructura producliva de esla aclividad agrícola y de las modificaciones inducidas por la reforma agraria de 1980.

Todos estos aspectos nos llevan a determinar el impacto negativo que tiene la caida de la producción algodonera en el producto interno bruto, en la generación de divisas y el empleo; a partir de las cuales trataremos de sehalar algunas consideraciones en torno a las perspectivas que tiene esta actividad en el futuro económico del país.

\section{Caracteristicas y tendenclas de la producción algodonera}

Como sefhalabamos anteriormente la profunda caida del área cullivada del algodón entre las cosechas 1978/79 y 1986/87 impactó seriamente esta actividad, de tal forma que entre estos anos la producción de algodón rama se redujo en un $86.4 \%$ y la de algodón oro en $85.1 \%$, es decir se redujo casi 7 veces entre estas dos cosechas. Existen un conjunto de factores asociados que explican la gravedad de la crisis algodonera, las cuales desarrollaremos más adelante.

Pero, a pesar de la caida en la producción de algodón durante estos anos, esla no parece haber afectado esencialmente sus rendimientos por manzana cultivada, ya que en promedio para cada una de las cosechas del periodo considerado se produjeron 30.25 quintales rama por manzana y 11.53 quintales oro por manzana. Comparativamente al perlodo 1970 a 1978 los rendimienlos si disminuyeron, ya que se producian 35.8 quintales rama por manzana anteriormente.

El peor año en rendimientos lue el considerado para la cosecha $1985 / 86$ ya que eslos disminuyeron en un $16 \%$ con respecto a la cosecha anterior, esto se debió a factores climatológicos que afectaron la producción en ese ano, especialmente el temporal que se presentó al inicio del corte.

Ora característica importante, es que el rendimienlo rama-oro se ha mantenido en un rango de 2.8 a 2.55 quintales rama por quintal oro, relación que es considerada adecuada en el proceso de producción de la fibra. 
Cuadro No. 1

Algodón: superilcle sembrada producción rama y oro (qq)

rendimlentos qq/mz. 1979/79 - 1986/87

\begin{tabular}{|c|c|c|c|c|c|c|}
\hline Cosecha & $\begin{array}{c}\text { Superficio } \\
\text { sembrada } \\
\text { Mz. }\end{array}$ & $\begin{array}{c}\text { Produccion } \\
\text { algodón } \\
\text { qq. }\end{array}$ & $\begin{array}{c}\text { Rendimiento } \\
\text { qq. Pama } / M z\end{array}$ & $\begin{array}{c}\text { Producción } \\
\text { Algodón oro } \\
\text { qq. }\end{array}$ & $\begin{array}{c}\text { Rendimiento } \\
\text { qq. oro/Mz. }\end{array}$ & $\begin{array}{c}\text { Relación } \\
\text { qq rama } \\
\text { qq oro }\end{array}$ \\
\hline $1978 / 79$ & 150.329 & 4.408 .267 .80 & 29.32 & 1.574 .639 .64 & 10.47 & 2.80 \\
$1979 / 80$ & 129.610 & 4.004 .810 .20 & 30.89 & 1.429 .994 .86 & 11.03 & 2.79 \\
$1980 / 81$ & 83.065 & 2.602 .871 .40 & 31.33 & 997.342 .04 & 12.00 & 2.61 \\
$1981 / 82$ & 82.750 & 2.397 .478 .40 & 28.97 & 912.681 .40 & 11.02 & 2.56 \\
$1982 / 83$ & 71.280 & 2.308 .315 .20 & 32.41 & 885.146 .58 & 12.41 & 2.60 \\
$1983 / 84$ & 54.423 & 1.690 .944 .27 & 31.07 & 656.238 .49 & 12.05 & 2.57 \\
$1984 / 85$ & 53.473 & 1.691 .161 .10 & 31.62 & 659.738 .84 & 12.33 & 2.56 \\
$1985 / 86$ & 39.931 & 1.040 .212 .50 & 26.05 & 407.578 .79 & 10.20 & 2.55 \\
$1986 / 87$ & 19.650 & 596.777 .20 & 30.37 & 234.161 .99 & 11.91 & 2.55 \\
\hline
\end{tabular}

Fuentw: Memorias Cooperativa Algodonera (COPAL).

Otro de los aspectos importantes de la producción algodonera esta referido a la cantidad y proporción producida de algodón oro según las calidades que se presentan en las distintas cosechas.

El algodón oro "es preparado en pacas o fardos que pesan aproxjmadamente 500 libras, después de haber pasado por la máquina peinadora y el condensador en le proceso de beneficiado".2

"Cada paca es analizada en el Departamento de clasificación de la Cooperativa Algodonera, usando para ello una muestra de 6 onzas y se hace separación en lipos o grados de algodón oro producido. Los grados que van de SUPRA a SALVA son considerados superiores y los de VERA a CHNR2 se ubican desde intermedio a inferiores"3.

Para las cosechas de $1978 / 79$ a 1986/87 el tolal de pacas clasificadas según grados se ha reducido en un $85 \%$, pasando de 314.801 pacas para la temporada $1978 / 79$ a 47.374 en la temporada 1986/87.

El algodón oro superior clasilicado entre el A-SUPRA y C2 SALVA represento un promedio de $76 \%$ de la producción; dentro de la clasificación los grados superiores C1-ANA y C2 SALVA estos participan con una mayor parte de la producción, alrededor del $68 \%$ lo constituyen eslos grados de algodón en el periodo de análisis.

El grado C1-ANA constituye en promedio para el período el $33 \%$ de la producción, mientras el C2-SALVA el $35 \%$, estos dos son los más importantes dentro de la producción algodonera. Por otro lado el grado ASUPRA considerado como el de máxima calidad, es el algodón superior 
con menor producción en el periodo, configura tan solo el $0.30 \%$ de la producción promedio del periodo.

En general una parte importante de la producción algodonera del pals esta constituido por calidades superiores, pero que han ido disminuyendo en términos de volumen de producción, para el caso la producción de algodón de grado superior en 1986/87 sólo representaba cerca de un $15 \%$ de la misma producción en la temporada 1978/79.

\section{Causas que expllcan el comportamlento de la producción}

Los factores que han incidido sobre la grave siluación por la cual atraviesa la producción algodonera y el impacto que esta tiene sobre otras aclividades económicas, asi como sobre el empleo agricola son múltiples y están relacionados entre sl. Entre estas causas podemos senalar:

a) Reducción de la rentabilidad del cultivo debido a diversos factores asociados: bajos precios en el mercado internacional; aumento de los costos de producción, de procesamiento, de comercialización y cosios linancieros de la COPAL; sobrevaluación acumulada del colón e incremento de precios de insumos importados, además de los efectos inflacionarios en los costos.

b) La insolvencia financiera de muchos productores debido a las pérdidas que durante varios anos obtuvieron, provocando esto la existencia de una considerable mora en el sistema financiero.

c) Insuficiencia del crédito en relación al aumento en los costos de producción y a su vez la aprobación tardla de dichos créditos, incidiendo eslo en la rentabilidad del cultivo.

e) La incidencia del proceso de reforma agraria en cuanto a la reorganización de la estructura agraria y baja en los rendimienlos en las unidades del sector reformado propiciando a su vez incertidumbre y disminución en la inversión.

d) La intensilicación del conflicto armado que afecta zonas productoras importantes de algodón, cuyos efectos en pérdida de cosechas y destrucción de infraestructura han propiciado la inseguridad $\theta$ incerlidumbre para invertir.

f) La presencia de algunas condiciones naturales adversas que se agravan con el inadecuado manejo de tierras y control de plagas.

En su conjunto todos estos factores han estado relacionados de tal manera que han provocado esta drástica disminución en el área cultivada y la producción. Tralaremos de evidenciar algunos de estos factores, a tin de comprender mejor este fenómeno. 
Cuadro No. 2

Cuadro comparativo de Pacas clafisicadas en las temporadas 1978/79 a 1986/87

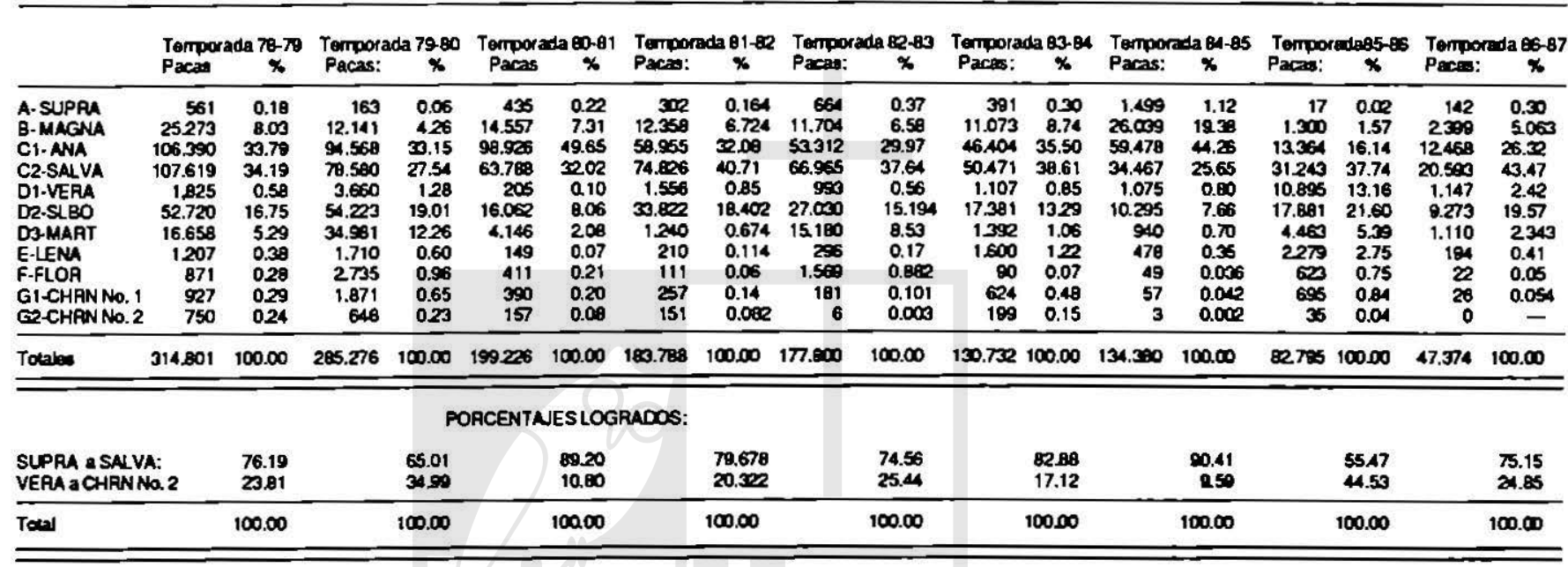

Fuente: Mernorias COPAL

(1)

$\stackrel{\oplus}{\mathbf{a}}$ 
Cuadro No. 3

Preclo promedlo por qq. rama, costos de producción por manzana

(Colones).

\begin{tabular}{|c|c|c|c|c|c|}
\hline Perlodo & $\begin{array}{c}\text { Precio qg. } \\
\text { Rama, }\end{array}$ & $\begin{array}{c}\text { Valor qq. rama } \\
\text { x manzana } \varsigma^{2}\end{array}$ & $\begin{array}{c}\text { Costo } \\
\text { Producc CxMz }\end{array}$ & $\begin{array}{c}\text { Dilerencia } \\
\text { Ingreso costo }\end{array}$ & $\begin{array}{c}\text { Relación } \\
\text { beneficio } \\
\text { costo 4/3 }\end{array}$ \\
\hline $1978 / 79$ & 67.41 & 1.976 .46 & 2.329 .87 & -353.41 & -15 \\
$1979 / 80$ & 69.19 & 2.137 .27 & 2.442 .70 & -305.43 & -12 \\
$1980 / 81$ & 77.97 & 2.442 .80 & 2.762 .87 & -320.07 & -11 \\
$1981 / 82$ & 61.49 & 1.781 .36 & 3.122 .13 & -1340.77 & -42 \\
$1982 / 83$ & 76.62 & 2.483 .25 & 3.397 .41 & -914.16 & -26 \\
$1983 / 84$ & 95.02 & 2.952 .27 & 2.901 .55 & +50.72 & +2 \\
$1984 / 85$ & 90.63 & 2.865 .72 & 3.152 .66 & -286.94 & -9 \\
$1985 / 86$ & 95.53 & 2.489 .55 & 3.651 .25 & -1162.7 & -31 \\
$1986 / 87$ & 128.85 & 3.913 .17 & & & \\
\hline
\end{tabular}

1. Precio qq rama determinado por COPAL

2. Precio del qq rama por la productividad promedio del año en qq rama de una manzana cultivada.

3. Costos de producción estimados y en base a dalos para el financiamiento de avio para las distintas cosechas.

Fuente:Memoria de la COPAL.

Costos estimados Dirección General de Economia Agropecuaria. Ministerio de Agricultura y Ganaderla.

\section{La rentabilldad del culílvo del algodón}

Uno de los factores más importantes que explican la caida en la superticie cultivada del algodón, es la relación entre los precios pagados al productor por QQ rama y sus cosios de producción.

Ep base a los dalos del cuadro No. 3 podríamos decir que los coslos de producción en promedio para lodos los años del periodo han sido superiores en un $24 \%$ a los ingresos obtenidos, es decir que por cada colón invertido en el cullivo de algodón se pierden 24 centavos. ${ }^{4}$

Tal como se evidencia en dicho cuadro hay una relación negativa entre los ingresos y costos para la mayoria de los ańos considerados, salvo el período 1983/84 donde la relación beneticio-costo solo representa 2 centavos de beneficio por cada colón invertido en el cultivo.

Estas condiciones desfavorables en el cultivo del algodón han provocado la lendencia a la disminución en el área cultivada y por lo tanto en la producción, aunque no en los rendimientos de producción por manzana, ya que estos se manlienen en un promedio anual durante el período de 11.53 qq oro por manzana.

El hecho de que la relación benelicio-costo sea negativo durante los 
primeros años del período (1978-87) y que este se acentúe para las cosechas 1980/81 y 1981/82 presentando tasas negativas de $-42 \%$ y $-26 \%$ respectivamente, generó unas expectativas deslavorables a incrementar el área cullivada del algodón.

Se ha señalado lambién que los costos de procesamiento del algodón, así como los de comercialización y financieros que controla la COPAL aumentaron durante estos afos; ciertamente los costos de operación de la COPAL aumentaron durante el período, de $₫ 16.43$ por quintal oro en la cosecha $1978 / 79$ a $₫ 74.69$ para la cosecha $1986 / 87$, el aumento en más 4.5 veces significaría para los productores precios menores por quintal rama, lo cual afeclaria seriamente sus posibilidades de rentabilidad en el cullivo.

El promedio de costos de COPAL ya sea por quintal rama u oro ha ido aumenlando en cada período, esto puede reflejar tanto la relación inversa que existe entre el volumen de producción y los costos de procesamiento y comercialización -es decir a menor volumen de algodón que entra al proceso de desmote los costos promedio van aumentandoque inciden sobre la renlabilidad del cultivo (Ver cuadro No. 4).

Cuadro No. 4

Relación costos totales de COPAL y producción qq rama y oro. colones por qq.

\begin{tabular}{|l|r|r|c|c|c|c|c|c|c|}
\hline Perlodo & $1978 / 79$ & $1979 / 80$ & $1980 / 81$ & $1981 / 82$ & $1982 / 82$ & $1983 / 84$ & $1984 / 85$ & $1985 / 86$ & $1986 / 87$ \\
\hline $\begin{array}{l}\text { Costo+ } \\
\text { qq rama } \\
\begin{array}{l}\text { Costos }+ \\
\text { qq oro }\end{array}\end{array}$ & 5.8 & 7.5 & 9.3 & 10.0 & 13.7 & 12.6 & 16.2 & 19.7 & 29.3 \\
\hline
\end{tabular}

Fuente: Memoria de Cooperastivas Algodoneras.

- Cálculos en base a los costos totales de la COPAL entre la producción rama y oro para cada cosecha.

- Los costos totales de COPAL ineluye coslos de procesamiento, comercialización y administrativos.

También habra que considerar que durante el periodo 1978-87 se ha ido incurriendo en nuevos cosios como son los servicios de seguridad que antes de 1980 no existian y estos se incrementan en la medida que el conflicto afecla las áreas algodoneras y su respecliva iniraestruclura, como ejemplo podemos cilar que para la cosecha 1983/84 el cosio de servicios de seguridad era de $₫ 649.989$ y se incrementa en más de $72 \%$ hasta llegar a $₫ 1.122 .192$ en la cosecha $1986 / 87$.

Los precios del algodón en el mercado internacional es olro factor importante a considerar en las expectativas de rentabilidad de los pro- 
ductores, si bien la comercialización de este producto esta a cargo de la Cooperativa Algodonera, los niveles de precios a los que se venden en el mercado internacional juegan en la fijación de los precios internos, vía la venta del algodón oro producido y la incidencia que tiene en los ingresos de la cooperativa.

La importancia que El Salvador tiene en el mercado mundial es muy pequeña, para el caso en 1978/79 la producción mundial del algodón fue de 49.83 millones de pacas (de $478 \mathrm{lbs}$ ); y la producción nacional (uno de los afios de mayor producción) fue de 329 mil pacas representando cerca del $0.7 \%$ de la producción mundial. Para este mismo año alrededor del $80 \%$ de la producción de algodón se exportaba.

Estos aspectos hacen de El Salvador esencialmente un país "tomador de precios", dada la poca iniluencia que tiene como oferente del produclo en el mercado mundial.

Cuadro No. 5

Preclos del algodón oro grado C1-Ana. FOB US \$ por quintal

\begin{tabular}{|c|c|c|c|c|c|c|c|c|}
\hline Año & Precio & $\%$ & Año & Precio & $\%$ & Año & Precio & $\%$ \\
\hline 1978 & 65.29 & - & 1981 & 81.13 & 3.8 & 1984 & 65.30 & -9 \\
1979 & 69.29 & 6 & 1982 & 66.08 & 18.5 & 1985 & 54.92 & -15.9 \\
1980 & 78.10 & 12.7 & 1983 & 71.93 & 8 & 1986 & 32.54 & -40.7 \\
\hline
\end{tabular}

Fuente: Revista del Banco Central de Reserva de El Salvador en base a dalos de COPAL.

Los precios del algodón oro, como se muestra en el cuadro No. 5 presentan oscilaciones importantes, los primeros años de 1978 a 1981 aumentan a una tasa promedio de $7.5 \%$, para 1982 disminuye el precio en $18.5 \%$ (de $\$ 81.13$ a $\$ 66.08$ ) con respecio al ano 1981 , en 1983 el precio se recupera en $8 \%$ con respecto al affo anterior.

Los siguientes anos de 1984 a 1986 se presentan las mayores bajas en los precios llegando a disminuir en el último año en $40.7 \%$. Cabe señalar que para 1987 el precio ha presentado una recuperación importanle llegando a alcanzar el valor de USD $\$ 62.89$ por quintal.

Ciertamente no parece presentarse una relación directa entre la disminución de la superficie cultivada y las oscilaciones de precios del algodón en el mercado internacional, ya que la caida tendencial del área cullivada está al mismo tiempo relacionado con los otros faclores antes senalados, lo que si habra que tener en cuenta es que precios al alza lienen incidencia en las perspectivas de los productores por beneficios estables y seguros y por lo tanto da posibilidades de inversiones más rentables, tal como sucedio en la década de los ' 70. 
La sobrevaluación del colón con respeclo al dólar que se mantuvo durante los primeros ańos del ' 80 se considero que luvo un impacto negativo sobre la rentabilidad del cultivo, "cálculos realizados por la misión de AID en 1984, cuando el tipo de cambio para la exportación de algodón era 2.5 colones por dólar, indicaron que en las condiciones existentes en aquel momento respecto al área lotal de siembra, rendimiento promedio, costos de producción, de procesamiento y de precios internacionales de venta, la única manera en la que el produclor promedio pudiera generar utilidades era liquidando la cosecha al tipo de cambio del mercado paralelo de entonces ( 3.85 colones por dólar)".5

El hecho que las auloridades monetarias acordaran en 1982 la creación del mercado paralelo y por lo tanto la flexibilidad del tipo de cambio, llevó poco a poco a trasladar las ventas de cierlos productos exportables al lipo de cambio paralelo. Las ventas de algodón al exterior, por lo tanto, entre 1984 y 1985 fueron trasladadas en su totalidad al mercado paralelo, posibilitando un diferencial cambiario que permilio ingresos de más de 26 millones de colones para la cosecha 1983/84 y de más de 41 millones de colones para la cosecha $1984 / 85$ a la cooperaliva algodonera.

Si bien, en 1986 se devalua el colón salvadorefro en un $100 \%$ ( $₫ 5=\$ 1$ ) este no propicio revertir la tendencia decreciente de la superticie cultivada de algodón, pero contribuyó parcialmente a resolver el problema de precios de los produclores.

La devaluación sin embargo incremento notablemente los precios de los insumos importados incidiendo negativamente en la rentabilidad esperada del cullivo.

El componente de insumos en la producción algodonera es de los más importantes dentro de la estructura de sus costos. Eslos estan constituidos fundamentalmente por semilla, lertilizanles e insecticidas; durante el periodo los precios de estos productos especialmente de lertilizantes $\theta$ insecticidas se han incrementado nolablemente afeclando asi la rentabilidad del cultivo.

El cuadro No. 6 muestra la importancia que dentro de la estruclura de costos tienen los insumos en la producción algodonera, entre el $30 \%$ y $35 \%$ constituye el componente de insumos, lo cuál significa que variaciones hacia el alza de los precios de estos productos puede ocasionar; una reducción en la aplicación adecuada de fertilizantes $\theta$ insecticidas que incide a su vez en el rendimiento de la producción por manzana. Pero también el productor puede asumir el incremento en los precios bajo el riesgo de una pérdida en la rentabilidad o beneficios del cultivo.

En 1984 membros de la COPAL sefialaban que "los costos de producción han aumentado especialmente por incrementos en el precio de 
Cuadro No. 6

Estructura porcentual de los costos

de producclón de algodón por manzana

\begin{tabular}{|l|r|r|r|r|}
\hline Rubros & $1978 / 79$ & $1983 / 84$ & $1984 / 85$ & $1985 / 86$ \\
\hline Insurnos & 35.4 & 28.4 & 30.7 & 34.3 \\
Preparación de tierra & 6.1 & 7.9 & 7.2 & 6.3 \\
Siembra de cultivo y & & & & \\
recolección & 32.7 & 38.5 & 38.9 & 35.8 \\
Administración & 2.2 & 2.3 & 2.4 & 2.4 \\
Imprevistos & 3.9 & 3.8 & 4.1 & 4.1 \\
Inlereses & 5.4 & 8.3 & 8.3 & 8.3 \\
Arrendarniento & 12.8 & 8.6 & 6.3 & 6.9 \\
Transporle & 1.0 & 1.9 & 1.8 & 1.6 \\
Seguro & 0.4 & 0.3 & 0.3 & 0.3 \\
& & & & \\
Total & 100.0 & 100.0 & 100.0 & 100.0 \\
\hline
\end{tabular}

Fuenle: Programa de Producción: Algodón, textiles y vestuario. MIPLAN 1986.

los fertilizantes e insecticidas, que constituyen casi el $45 \%$ de los costos totales". 6

Dentro de los insumos utilizados por manzana, la semilla solo constituye cerca del $2 \%$ del costo de este rubro, en cambio los fertilizantes representan entre el $25 \%$ al $35 \%$ y los insecticidas entre el $65 \%$ al $75 \%$ del componente insumos para la producción algodonera (Ver cuadro No. 7).

Cuadro No. 7

Estructura porcentual de Insumos utllizados por manzana en la producción de algodón

\begin{tabular}{|l|r|r|r|r|}
\hline Rubros & & & & \\
\hline Sernilla & $1983 / 83$ & $1983 / 84$ & $1984 / 85$ & $1985 / 86$ \\
Fertilizante simple & 1.87 & 1.74 & 1.90 & 1.47 \\
Fertilizante compuesto & 9.61 & 20.90 & 11.94 & 10.61 \\
Foliares & 13.34 & 10.94 & 12.74 & 11.33 \\
Insecticidas & $\overline{-}$ & $-\overline{2 .}$ & 2.27 & 2.02 \\
Herbicidas & 70.73 & 60.95 & 67.21 & 71.08 \\
Olros & 3.56 & 5.47 & 3.93 & 3.49 \\
& 0.89 & - & - & - \\
Total & & & & \\
\hline
\end{tabular}

Fuente: Programa de Producción: Algodón, textiles y vestuario. MIPLAN 1986. 
En base a lo anteriormente considerado analisemos las variaciones en los precios algunos de los fertilizantes e insecticidas para apreciar el impacto que tiene sobre los costos de producción y la rentabilidad.

Duranle los años 'BO la lasa de inllación ha presentado aumentos considerables, tal es asi que el promedio general para los distintos años es de $18.3 \%$ y el incremento acumulado de los precios es de más de $146 \%$ entre 1980-1987, es de esperar que entre 1980-1987, es de esperar que esta tendencia tenga efectos importantes sobre los precios de los insumos básicos de la producción algonera.

El cuadro No. 8 muestra como los precios de los fertilizantes e insecticidas han ido aumentando, especialmente para las últimas cosechas, el hecho que gran parte de estos insumos sean importados, así como la adopción de políticas cambiarias que a partir de 1982 propiciaran el "deslizamiento" del colón salvadoreño con respecto al dólar hasta llegar a una devaluación efecliva del $100 \%$ en 1986, alecló seriamenle los precios de estos productos.

Es de considerar que alguno de estos insumos fueron controlados en sus precios y comercialización por el gobierno a través del Banco de Fomento Agropecuario y la Federación de Cajas de Crédito, además de tipos de cambio prelerenciales, durante el periodo que el colón fluctuó flexiblemente, pero a partir de la devaluación el impaclo fue generalizado salvo por aquellas donaciones o ayuda en insumos recibida por el gobierno.

En general el impacto de la inflación, asi como de la devaluacion del colon en los precios de los fertilizantes e insecticidas, incrementó los costos de producción y por lo tanto las posibilidades de mayor rentabilidad del cultivo.

\section{Crédito e Insolvencla tinanclera}

El crédito a la agricultura es considerado un factor importante para el desarrollo de las diferentes actividades produclivas, para el caso del algodón se plantea que ha habido una insuficiencia de crédito para cubrir los coslos de producción, lambién se dice que eslos crédilos han lenido una aprobación tardía incidiendo asi negativamente en la rentabilidad del cultivo.

Se considera también que exisle una mora muy grande en el sistema financiero debido a que los productores de algodón obtuvieron pérdidas en las cosechas anteriores.

En su conjunto los lactores crediticios lienen un papel importante en el desarrollo de la actividad algonera, por to que sefalaremos que el linanciamiento a esta actividad esta dividido en dos lases: a) para la fase de producción agricola y b) para la comercialización. 


\section{Cuadro No. 8}

Preclos de algunos Insecticldas y fertilizantes ofrecidos por COPAL a productores de algodón on 4 .

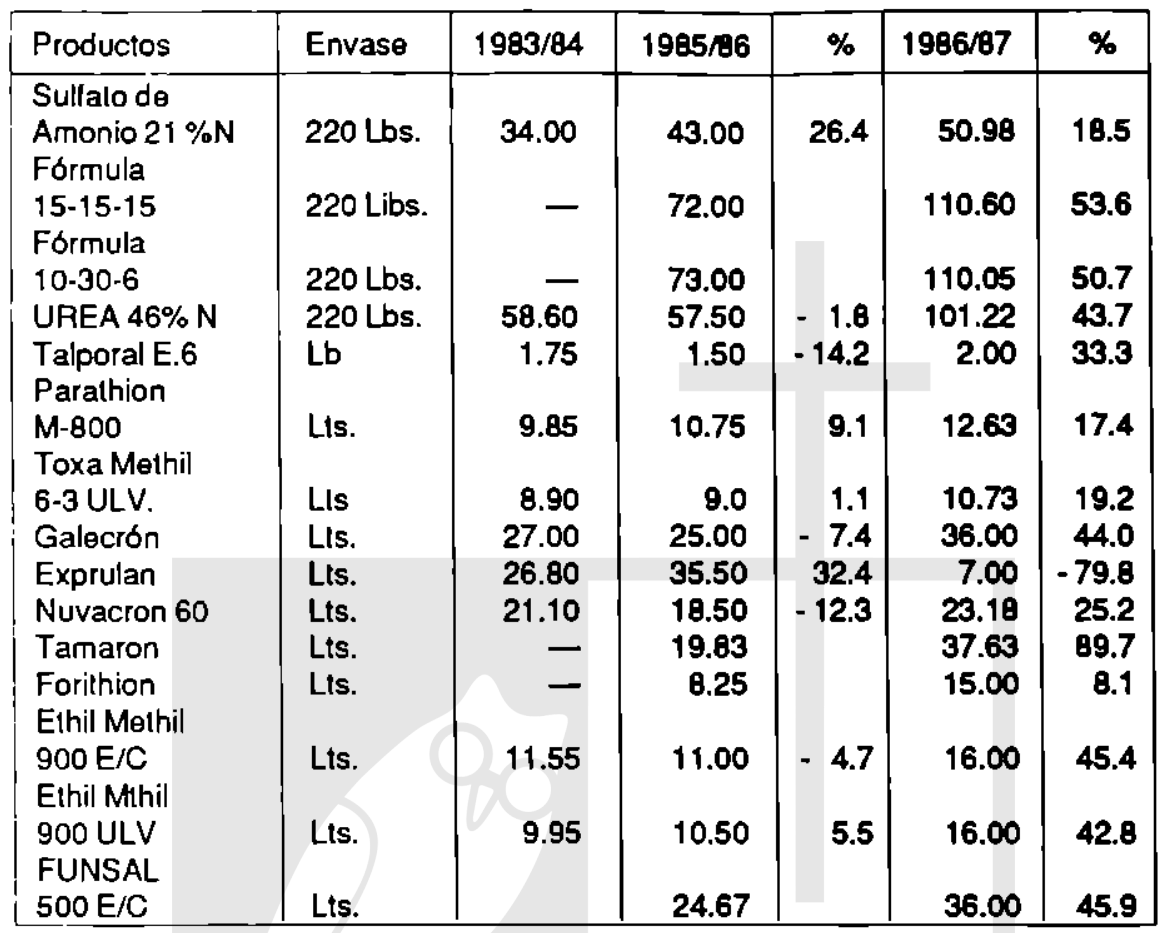

Fuente: Memorias de la Cooperativa Algodonera.

Las fuentes credilicias del sector algodonero son:
a) El sislema bancario nacional, que abarca el Banco Central de Re- serva, la Banca Mixla Comercial, el Banco de Fomento Agropecuario.
b) Federación de Cajas de Crédito.
c) Cooperativa Algodonera Salvadoreña Limitada.
d) Proveedores Agropecuarios (casas comerciales de fertilizantes y pes- ticidas).
e) Empresas de Servicio Aéreo para riego de insecticidas y distribui- dores de maquinaria.
f) Intermediarios.
g) Prestamistas.
El crédito orienlado a la actividad algodonera entre 1980-84 por las diversas instituciones linancieras seleccionadas (Cuadro No. 9), mues- Ira una tendencia decrecienle, esta siluación esta relacionada a la per- sislente caida d ela superficie cultivada y la producción de algodón. 


\section{Cuadro No. 9 \\ Crédito a la actividad algodonera por Instituciones 1980-64 \\ (Millones de colones)}

\begin{tabular}{l|r|r|r|r|r|r|r|r|r|r|r}
\hline Instituciones & 1980 & $\% 1$ & 1981 & $\%$ & 1982 & $\%$ & 1983 & $\%$ & 1984 & $\%$ & $\begin{array}{c}\text { Tasa de crecimiento } \\
\text { promedio anual. }\end{array}$ \\
\hline $\begin{array}{l}\text { Banco Central } \\
\text { de Reserva } \\
\text { Banca Mixta } \\
\begin{array}{l}\text { Comercial } \\
\text { Banco }\end{array}\end{array}$ & 114.9 & 23.0 & 164.5 & 26.5 & 114.9 & 27.3 & 77.8 & 21.3 & 85.8 & 22.4 & $-7.0 \%$ \\
$\begin{array}{l}\text { Hipotecario } \\
\text { Banco de Fomento }\end{array}$ & 75.6 & 30.3 & 94.6 & 32.7 & 133.9 & 22.8 & 66.2 & 13.3 & 139.9 & 21.7 & $16.6 \%$ \\
$\begin{array}{l}\text { Agropecuario } \\
\text { FEDECREDITO }\end{array}$ & 58.6 & 31.8 & 69.5 & 27.9 & 64.2 & 25.6 & 45.0 & 22.8 & 36.9 & 20.5 & $-13.1 \%$ \\
\hline
\end{tabular}

1. Porcentajes en relación al flujo de crédito agricola tolal de cada institución.

Fuente: En base a iniormación proporcionada por las insbituciones, tomado de "Mercados Financieros Rurales de EI Salvador (movilización de ahomos y créditos agropecuarios) ' Preparado para USAID/ EI Salvador por Contrating Corporation of America. Inlorme final elaborado por Ladman, J., Torrico, Iy Bince, T. W. 1986. 
La banca mixta comercial es la única, en lérminos de instituciones, que presenta un crecimiento positivo del crédito a la aclividad algodonera, mostrando una tasa de crecimiento promedio anual de $16.6 \%$. El Banco Central de Reserva, el Banco Hipolecario, el Banco de Fomento Agropecuario y la Federación de Cajas de Crédito han disminuido en forma importante las asignaciones de crédilo a la aclividad algodonera.

Siguiendo las caracterislicas de la esinuctura de crédito de las instituciones linancieras, estas seguian concentrando el crédito a los cultivos de exportación; y viendo más especilicamente el crédito agrícola al algodón este constituye para el Banco Central entre el 20 al $27 \%$ del lotal de crédito asignado a la agricultura. Para la banca mixta comercial el crédito al algodón representa más del $24 \%$ en promedio de su crédito agropecuario, las mismas proporciones presenta el Banco Hipotecario para el perlodo 1980-84.

Para inslituciones como el Banco de Fomento Agropecuario así como para la Federación de Cajas de Crédito la proporción del crédito al algodón es de $14 \%$ y $5 \%$ respectivamente, en promedio para los años de 1980-84.

Lo importante de estas características es que el llujo de crédilo al algodón si bien ha sido decreciente, aun asl este ha representado una parte significativa del crédilo agrícola de las distintas instituciones.

Según dalos proporcionados por las instiluciones financieras, estimando los costos de producción por manzana de algodón estas habrian autorizado montos de financiamiento que cubrian alrededor del $81 \%$ de dichos coslos para las cosechas entre 1982-86.

Cuadro No. 10

Financlamiento del avio al algodón durante perlodo

\begin{tabular}{|l|c|c|c|c|}
\hline Periodos & $\begin{array}{c}\text { Costo estima- } \\
\text { do por Mz. }\end{array}$ & $\begin{array}{c}\text { Monto autoriza- } \\
\text { do por Mz. }\end{array}$ & $\begin{array}{c}\text { Tasa de } \\
\text { interés }\end{array}$ & $\begin{array}{c}\text { Cobuertura de } \\
\text { crédito }^{2}\end{array}$ \\
\hline $1982 / 83$ & 3.326 .21 & 2.508 & 13 & 75.40 \\
$1983 / 84$ & 2.901 .55 & 2.584 & 13 & 89.05 \\
$1984 / 85$ & 3.152 .66 & 2.736 & 13 & 86.78 \\
$1985 / 86$ & 3.651 .25 & 2.774 & 13 & 75.97 \\
\hline
\end{tabular}

1.Para productores que cultivan tierras propias. Los agricultores que cultivan tierras arrendadas pueden oblener un financiamiento adicional de $\& 250 \times$ manzana para el pago de amendamiento.

2. Cobertura en relación al financiamiento para propietarios de terras, para los arrendatarios el porcentaje de financiamiento se eleva con el valor de arrendamiento de tierras.

Fuente: Banco Central de Reserva. Comunicaciones a los Bancos del Sisterna, sobre IIneas de financiamiento establecidas.

Estructura de costos establecida por la Dirección de Economla Agropecuaria. Ministerio de Agrlcultura y Ganaderla. 
La cobertura de los créditos para la producción algodonera cierlamente no es del $100 \%$ de sus coslos, pero es un porcentaje importante de ellos, de tal manera que el productor puede contar con un crédito suficiente para el desarrollo de su actividad.

Al respecto en un estudio sobre el algodón se sefiala que el Banco Central, ha puesto a disposición del algodonero, financiamiento suficiente y adecuado para cubrir un porcentaje de los costos de producción estimados del cultivo; además que el BCR ha hecho algunos ajustes en periodos de cosecha concediendo ampliaciones como por ejemplo en la cosecha 1983/84, se concedió $₫ 2.00$ por quintal rama adicional, debido al incremento de costos de insumos y su aplicación, y $₫ 2.00$ más por quintal rama dependiendo de las necesidades extraordinarias identificadas por el departamento agropecuario y de supervisión de los bancos".7

En cuanto a la relación enlre la aprobación y puesto a disposición del productor del crédito de avio; según información de las fechas de aprobación de líneas de calilicación y redescuenlo dados por el Banco CenIral, no habria un desfase entre las fechas de aprobación y las fechas de iniclación de labores en el cultivo del algodón.

Cuadro No. 11

BCR. Fechas de aprobación de lineas de callflcación y redescuento para avio agricola.

\begin{tabular}{|l|l|}
\hline Anos agricolas & Fecha de resolución \\
\hline $1982 / 83$ & 4 de marzo de 1982 \\
$1983 / 84$ & 3 de febrero de 1983 \\
$1984 / 85$ & 1 de marzo de 1984 \\
$1985 / 86$ & 28 de febrero de 1985 \\
\hline
\end{tabular}

Fuente: BCR. Comunicaciones a los Bancos del Sistema.

Lo cual quiere decir que "cualquier retraso en el olorgamiento de créditos puede eslar dado por el hecho de que el algodonero no ha cancelado su compromiso anterior, o debido al retraso en la presentación de documenlos indispensables para el trámile y período que cada banco requiere para la aprobación del crédito al clienle."

No obstante se considera que las instituciones financieras cuentan con mecanismos especiales para atender las necesidades de clientes que tienen un buen record en términos de cumplimiento de sus créditos.

Según las reglamentaciones del BCR se establece que la primera 
labor que requiere inversión por parte del algodonero es la chapoda o desirucción de rastrojos, esta labor es considerada dentro del crédito de avío de cada afio y que el financiamiento es olorgado anlicipadamente, pero sucede que las instituciones financieras incumplen de forma $y$ periodo de entrega (enero de cada año) y el algodonero hace uso incorrecto de esla disponibilidad. ${ }^{9}$

En general parecen existir problemas en la disposición y uso del crédito dado por las instituciones financieras al productor, en muchos casos la mora del productor es un freno a una mejor accesibllidad al crédito, pero también es necesario considerar que pueden haber desfases entre la fecha de cancelación del crédito y la liquidación que de la producción hace la Cooperaliva Algodonera al productor, aspecto que puede provocar la mora del productor con el sistema financiero.

El problema de la mora de los productores parece haberse convertido en un freno al incremento en la superticie cultivada del algodón, este tenómeno podría percibirse a través del refinanciamiento de los préstamos olorgados a los produclores de algodón.

Antes de analizar las tendencias del refinanciamiento a la actividad algodonera, es necesario aclarar cual es el objetivo del relinanclamiento para este lipo de produclos, al respecto un estudio sobre los mercados financieros rurales en El Salvador dice que "el objelivo del retinanciamiento es cambiar la deuda de un préstamo de producción a un préstamo prendario, garanlizado por un producto agricola, mientras el procesamiento y mercadeo se llevan a cabo". Este tipo de crédito refinanciado es usualmente para un perlodo de menos de un año, por to lanto es de corto plazo".10

El mismo estudio sef́ala que "La Junta Monetaria y el BCR han creado líneas de crédito especiales para refinanciamienlo,... los refinanciamientos de las malas deudas han tomado particular importancia desde 1979. La relorma agraria, problemas con las Cooperallvas de la Fase I, la guerra civil..., asl como varios anos de mercados pocos favorables para productos de exportaciones tradicionales han causado altos niveles de mora. En vista de eslos problemas externos $\theta$ inusuales, el gobiemo ha tomado la posición de ser muy liberal para extender refinanciamiento de deudas en mora a tasas de interés favorables y preferenclales. Aún cuando existen buenos argumentos económicos para hacer esto, muchas de las decisiones han sido en razones de conciencia política y social. El refinanciamiento reduce la inestabilidad polltica del pals. Además a mantenido las cooperativas de la Fase I del seclor reformado elegibles para más crédito. Si esto no se hubiese realizado el programa de reforma agraria hubiera peligrado seriamente."11

Los préslamo refinanciados estan concentrados en los cultivos de 
exportación tradicional, un considerable monto representa relinanciamiento a corto plazo asociado al procesamiento y comercialización de los productos y una porción importante representa refinanciamiemto a largo plazo de préslamos en mora.

En el caso de relinanciamiento al algodon, el Banco Central ha ido reduciendo este a una lasa de $9.6 \%$ anual entre 1980 a 1984 y por lo lanto disminuyendo en lorma signiticativa la proporción que este conslituye de la cartera de refinanciamiento de préstamos agricolas.

La Banca Mixta Comercial asl como el Banco Hipolecario presentan una tasa de crecimiento anual de $21.6 \%$ y $27.1 \%$ respectivamente para refinanciamiento de la actividad algodonera durante el periodo de 198084. El retinanciamiento al algodón constitula para la Banca Mixta Comercial hasta 1982 una proporción importante de su cartera agricola refinanciada (64.2\%), para 1984 esta proporción ha sido reducida a 6.7 $\%$, lo cuál esla relacionada a la drástica caida del cultivo en los últimos años. En cambio para el Banco Hipotecario sigue representando el refinanciamiento al algodón un $25 \%$ de su cartera agricola refinanciada.

En los casos del Banco de Fomento Agropecuario y FEDECREDITO no se puede delerminar exactamente el relinanciamiento a la actividad algodonera, pero sl el refinanciamiento de sus préstamos ha crecido a $67.4 \%$ y $26.1 \%$ como promedio anual (1980-84) para cada una de estas instituciones.

En general la morosidad se ha ido constituyendo en un problema para las instituciones tinancieras, cientamente los factores como la crisis, el conflicto, etc, han afectado la producción y reducido la rentabilidad de los cullivos, propiciado el desarrollo de este fenómeno.

Los productores de algodón durante estos úllimos anos han sido favorecidos por refinanciamienlo a fin de cubrir la morosidad que tenlan, monlos grandes de refinanciamiento han sido a largo plazo to cual significa que el problema de la morosidad ha sido pospuesto, pero sus efectos se sentiran en las instituciones linancieras en el luturo.

En general al respecto del problema del crédito y de la insolvencia de los produclores de algodón podríamos concluir que si bien el sistema financiero ha proporcionado facilidades crediticias, refinanciamientos, etc. El problema de la morosidad y la caida del cultivo del algodón está asociado a lactores fuera del control de estas instituciones (crisis económica, conflicto, elc) y de los productores.

\section{Disminuclón en la Inversión e Incertidumbre provocada por el conillicto y la reforma agrarla}

A partir de 1980 la agudización del conflicto social y polflico en la 
Cuadro No. 12

Refinanclamiento de algodón por el BCR, Banca Mixta Comercial e Hipotecarla y retinnanclamiento total del BFA y Fedecredito en millones de colones

\begin{tabular}{|l|r|r|r|r|r|r|r|r|r|r|c|}
\hline Instiluciones & 1980 & $\%^{2}$ & 1981 & $\%$ & 1982 & $\%$ & 1983 & $\%$ & 1984 & $\%$ & $\begin{array}{c}\text { Tasa de crecimiento } \\
\text { promedio anual. }\end{array}$ \\
\hline $\begin{array}{l}\text { Banco Central } \\
\text { de Reserva } \\
\text { Banca Mixta }\end{array}$ & 163.4 & 62.2 & 120.7 & 21.0 & 62.6 & 22.5 & 95.6 & 10.2 & 109.3 & 10.0 & $-9.6 \%$ \\
Comercial & 8.1 & 14.6 & 5.5 & 6.3 & 64.2 & 27.2 & 34.7 & 14.6 & 17.7 & 6.7 & $21.6 \%$ \\
$\begin{array}{l}\text { Banco } \\
\text { Hipotecario }\end{array}$ & 18.8 & 27.6 & 22.5 & 22.8 & 43.0 & 26.4 & 48.6 & 22.7 & 49.1 & 27.0 & $27.1 \%$ \\
$\begin{array}{l}\text { Banco de Fornento } \\
\text { Agropecuario1 }\end{array}$ & 10.1 & 3.2 & 11.4 & 4.3 & 25.7 & 10.9 & 54.2 & 16.1 & 79.3 & 18.9 & $67.4 \%$ \\
FEDECREDITO & 2.5 & 6.2 & 5.8 & 13.0 & 1.9 & 5.1 & 6.6 & 26.8 & 6.4 & 25.6 & 26.1 \\
\hline
\end{tabular}

1. Se considera el lotal del refinaneiamiento otorgado por estas instituciones, considerando especialmente las actividades agricolas. No se pudo desglosar la parte correspondiente al algodón.

2. Porcentajes sobre el tobal del refinanciamiento a préstamos agricolas (BCR, BH y BMC). Porcentajes del refinanciamiento en el tolal del crédito de la institución BFA y FEDECAEDITO.

Fuente: Op. Cit. Mercados financieros rurales en EI Salvador..., elaborado en base a los datos de las distintass instituciones. 
Cuadro No. 13

Financlamiento para pagos de saldos Insolutos del algodón

\begin{tabular}{|c|l|c|c|}
\hline Años & $\begin{array}{c}\text { Cosecha } \\
\text { Refinanciar }\end{array}$ & $\begin{array}{c}\text { Tasa de } \\
\text { interés }\end{array}$ & $\begin{array}{l}\text { Plazo } \\
\text { afios }\end{array}$ \\
\hline 1982 & $\begin{array}{l}1978 / 79 \\
1979 / 80\end{array}$ & $11 \%$ & 8 \\
1983 & $1982 / 83$ & $13 \%$ & 8 \\
$1984^{2}$ & Saldos insolutos & $6 \%$ & 4 \\
1985 & Saldos insolulos & $10 \%$ & 6 \\
\hline
\end{tabular}

1. Saldos vencidos más intereses o saldos vigentes más intereses de crédilo con recursos propios de los bancos o del BCR.

2. Linea especial para sector agrario relormado.

Fuenle: BCR. Comunicación a los Bancos del Sitema.

sociedad salvadoreña se manifestará en una guerra civil que tiene más de ocho afios de duración, la destrucción que ha causado esta guerra, asi como sus electos en términos de vidas humanas y profundización de la crisis económica, ha trascendido también al ámbito de la aclividad agricola y especílicamente a la producción algodonera.

Este mismo año (1980) marca el inicio del proceso de reforma agraria, que a través de la expropiación de tierras trala de establecer y fomenta rnuevas formas de organización de la producción en la agricullura.

Estos dos aspectos - confliclo armado y reforma agraria- tendrán un signilicado imporlante en el desarrollo de la actividad algodonera, dado que crearan expectativas de inseguridad e incertidumbre a los produclores para nuevas inversiones; por un lado la guerra ha incidido en la destrucción de cultivos, cosechas e infraestruclura de productores que se ubican en zonas de alla conlliclividad militar. Mientras por otro lado la reforma agraria supuso todo un proceso de reorganización adminisIrativa, adecuación de los intereses de cooperalivislas, expropiación de lierras, cambios en las formas de organización de la producción, que incidieron en general sobre la actividad producliva del algodón.

Para evidenciar algunos de estos aspectos podemos seffalar que los daf́os direclos ocasionados por la violencia en el sector agropecuario salvadorefio entre 1980-84 se estimaron en más de 625 millones de colones de los cuales COPAL había reporlado hasta "diciembre de 19834.5 millones de colones en dafíos, en 1984 se habian destruido 150 manzanas de algodón de 3 meses de desarrollo valorados en 100 mil colones, y 
se había destruido 1.500 pacas de algodón en el Plantel "El Martillo", Usululán en el mismo afio valoradas en 1.2 millones de colones".12

Los dafios considerados por quemas de cosechas, producción perdida y destrucción de infraestructura propia a la producción algodonera creo un clima de incertidumbre que fue reduciendo el cultivo del algodón.

A los daños directos habra que agregar el impacto que liene los efectos destructivos de la violencia indirectamente en la producción, procesamiento y comercialización del algodón.

La destrucción de puentes, carreteras, del sistema de transporte (ferroviario y automotriz), los danos al sistema de energía y comunicaciones, asi como a los servicios públicos, el comercio y la industria, tienen efectos indirectos que si bien no se pueden cuanlilicar pero inciden sobre las distintas actividades económicas y por lo tanto en la producción algodonera.

La guerra civil ha provocado una destrucción de infraeslnuctura que se estima superior a los 2.000 millones de dólares. Esto realmente se convierte en un factor desestimulador de la actividad productiva.

El otro aspecto esta referido a la reforma agraria la cual como se sefiala anteriormente supone un periodo de readecuación y cambios que propician en muchos casos reducción en los niveles de productividad y producción agrícola. Pero además creó un clima de incertidumbre ante las posibilidades de fuluras alectaciones a la propiedad privada (Fase II).

La incerrlidumbre e inseguridad derivada del confliclo y la relorma agraria, vinculado esto a otros factores económicos negativos provocaron en los productores de algodón fuertes contracciones en sus niveles de inversión, que se reflejan en la caida de la superficie cultivada y la producción.

\section{Condlciones naturales adversas e Inadecuado manejo de tlerras y control de plagas.}

Durante el período analizado una serie de fenómenos climatológicos afectó los cultivos de algodón por ejemplo para la cosecha "1982-83 un temporal de 4-5 días con lluvias intensas inundo muchos campos algodoneros"13. Para la cosecha 1985-86 se informó que uno de los factores que atectó especialmente "las calidades obtenidas, fue el temporal que precisamenle se desencadenó al inicio del corte"14 y para la cosecha 1986-87 la sequia que se presento a tinales del ano 1987 provocó pérdidas en la producción algodonera, ya que no propicio el desarrollo normal de la planta y por lo tanto los rendimientos esperados. 
A estos factores climatológicos se sumaron, las deliciencias que se presenló en el manejo del suelo y el control de plagas los cuales crearon también fuertes disminuciones en la producción. Ciertamente la crisis económica y los factores anteriormente sefalados propiciaron un abandono de prácticas agroecológicas que son importantes para el desarrollo de la producción algodonera, es decir, aquellas prácticas que lienen que ser con la limpiza del suelo, el riego, la fertilización, la aplicación adecuada de plaguicidas, la siembra, elc. fueron durante este período reducidas o abandonadas provocando así un deterioro de la producción de algodón.

\section{Caracterisilcas del mercado del algodón}

Para el análisis del mercado del algodón habra que considerar por un lado la oferta de este, que estaria constituido por la producción y las importaciones, por otro lado tendriamos la demanda que considera las exportaciones las ventas al mercado nacional.

La presencia de una serie de factores adversos en los últimos afios han hecho que estos componentes del mercado presenten graves debilidades. La crisis económica, el confliclo militar y la siluación negativa de los mercados internacionales para nuestros productos han afectado seriamenle las condiciones del mercado algodonero.

\section{Producclón e Importaclones}

La producción algodonera tradicionalmente ha respondido a las necesidades internas y extemas de la demanda, pero es necesario sefalar que en los dos últimos ańos considerados en las cosechas 1985/86 y $1986 / 87$, las empresas lextiles tuvieron que recurrir a importaciones debido a la profunda caida de la producción algodonera.

La producción presenta de 1978 a 1987 una tendencia decreciente, (ver cuadro No. 14) la tasa promedio anual de disminución es de - $14.7 \%$ en el período. Habiendo presentado solamente en 1978 y 1983 tasas posilivas de crecimiento.

El año 1978 es precisamenle el de más alta producción en la década de los 70 , este se convierte por lo lanto en el punto de referencia y marca la inflexión que se presenta en la producción algodonera.

La producción de algodón de 1987 representa tan sólo el 15\% del tolal generado en 1978, es decir se redujo en más de 6 veces en este periodo.

Los factores incidentes en esta drástica caida han sido evidenciados anteriormente y parecen no presentar todavía sintomas de recuperación en la actualidad.

Si bien la producción de algodón de 1987 es estimada, podriamos 
Cuadrro No. 14

Algodón: Producclón por afio calendarlo (en quintales).

\begin{tabular}{|l|c|c|c|c|c|c|c|c|c|c|}
\hline Ano & 1978 & 1979 & 1980 & 1981 & 1982 & 1983 & 1984 & 1985 & 1986 & 19071 \\
\hline Producsión OO & 1.712 .029 & 1.410 .486 & 1.349 .647 & 984.003 & 070.313 & 085.956 & 683.991 & 541.700 & 350.900 & 269.900 \\
\hline $\begin{array}{l}\text { Tasa de } \\
\text { cocimienlo }\end{array}$ & 12.5 & -17.5 & .4 .3 & -27.0 & .11 .5 & 1.8 & .22 .7 & .20 .8 & .352 & .23 .0 \\
\hline
\end{tabular}

Fuente: Estadlstica del Banco Central de Reserva de El Salvador.

1. Proyección. Producción estimada del sector agropecuario para 1987.

considerar que la sequía que se presenlo en esle ano afectó el cullivo del algodón no permitiendo en ciertas zonas el desarrollo completo del ciclo agrícola de la planta del algodón.

Solamente el año 1983 presenta una tasa positiva de crecimiento de $1.8 \%$ pero no reflejó las posibilidades de revertir la caida de la producción.

En general podemos considerar que la tendencia hacia la baja en la producción algodonera seguirá, ya que los factores propiciadores todavía estan presentes (bajos precios internacionales, aumento costos de producción, etc.) y que posibilidades de incremenlos leves en la producción podrian ser posibles siempre que se traten de resolver algunos problemas que afectan esle cullivo.

El Salvador Iradicionalmente ha sido, desde hace varias décadas, esencialmente exportador de fibra de algodón llegando a alcanzar niveles exportables significativos en la década de los '70; el mercado interno nacional ha sido pues sulicienlemente abastecido por la producción local.

A partir de la decada de los ' 80 , como se ha evidenciado anteriormente, la superticie cullivada y la producción se han ido reduciendo a un ritmo my acelerado debido a causas ya explicadas. Esta situación ha ido provocando dificullades para suplir las necesidades de la industria textil en cuanto a las canlidades y calidades requeridas de la libra para su proceso productivo.

No solamente se ha visto afectada con esta reducción la industria textil sino también las empresas productoras de la rama alimenticia, que utilizan la semilla de algodón como insumo. Es necesario considerar que la crisis económica por la que atraviesa El Salvador ha incidido también en la aclividad induslrial y especificamente en la industria textil generando así contracción en el consumo interno de la fibra, al respecto se senala comparando los años 1984 y 1985 "el acumulado anual vendido al mercado local fue de 279.649 quintales (1985) por un valor de 63.4 millones de colones; mientras que para 1984 el volumen vendido se cifró 
en 291.847 quintales a un valor total de 60.7 millones de colones."15

"Esta situación refleja una disminución del $4 \%$ en el volumen de libra de algodón adquirido inlernamente y de un incremento de $4.4 \%$ en el valor tolal de las compras en 1985". 16

A pesar de las contracciones que presenta el mercado inlerno, el ritmo de decrecimiento de la producción de algodón es mayor y la presencia de factores coyunturales a cada cosecha ha provocado dificultades en el abaslecimiento del mercado nacional.

Al respecto la COPAL iniormaba "uno de los factores que más afectó en el Ejercicio 1985/86, principalmente en lo referenle a las calidades oblenidas, fue el lemporal que precisamente se desencadeno al inicio del corte, lo cual influyó grandemente en la comercialización, principalmente al negociarse la reserva con las hilanderias locales, que requieren de nuestras mejores calidades para cumplirles su reserva, obligando esta siluación a que por primera vez se electuaran importaciones masivas de algodón oro por parte de la industria nacional."17

Así mismo se informaba para el mismo ejercicio que "debido a la baja producción y siniestros, no se pudo atender la demanda del consumo local, en lo que se reliere a cantidades de los grados que procesan, por lo que: Hilanderías y Textileros se vieron en la necesidad de imporlar fibra producida en el extranjero."18

Según información del Banco Central para 1986 se habia importado algodón sin cardar ni peinar en un volumen de $491.771 \mathrm{Kgs}$ (10.690 quintales) por valor de 2.656 .980 colones. Esto podría representar cerca del $4 \%$ de las ventas de la COPAL al mercado nacional que fue de 306.901 quintales para la cosecha 1985/86..$^{19}$

Para la cosecha 1986/87 la COPAL en referencia al mercado nacional informaba que "la reserva de algodón para fábricas de Hilados y Tejidos lue de 39.521 pacas, y se efectuó de acuerdo a la producción y calidades oblenidas durante la cosecha 1986/87. Dado que la reducción de la cosecha que no cubria sus necesidades, nuevamente recurrieron a la importación de libra."20

En general los dos últimos años, la induslria textil nacional ha tenido que recurrir a importaciones de fibra dada la dificultad que atraviesa la producción algodonera.

\section{Exportaclones y ventas en el mercado interno}

Las exportaciones del algodón para el periodo de 1978-86 han presentado oscilaciones importanles; lo que parece muy relevante es la caida de las exporlaciones en más de 10 veces, es decir habia disminuido en un $90 \%$ entre 1978 a 1986 en relación a su valor monelario. 
Cuadro No. 15

Exportaclones de algodón 1978-1986

\begin{tabular}{|c|c|c|c|c|}
\hline ano & $\begin{array}{c}\text { Valor } \\
\text { (millones } \pitchfork \text { ) }\end{array}$ & $\begin{array}{c}\text { Variación } \\
\text { \% valor }\end{array}$ & $\begin{array}{c}\text { Volumen } \\
\text { (miles de Kgs.) }\end{array}$ & $\begin{array}{c}\text { Variacion } \\
\text { \% Valor }\end{array}$ \\
\hline 1978 & 251.2 & 24.2 & 88.840 .7 & 42.6 \\
1979 & 217.5 & -13.4 & 66.526 .8 & -25.1 \\
1980 & 217.9 & 0.18 & 62.240 .6 & -6.4 \\
1981 & 137.9 & -36.7 & 36.352 .9 & -41.5 \\
1982 & 115.7 & -16.0 & 37.033 .0 & 1.8 \\
1983 & 140.7 & 21.6 & 40.208 .0 & 8.5 \\
1984 & 25.9 & -81.5 & 8.308 .0 & -79.3 \\
1985 & 76.9 & 196.9 & 28.113 .0 & 238.3 \\
1986 & 24.6 & -68.0 & 7.772 .0 & -72.3 \\
\hline
\end{tabular}

Fuente: Revista del Banco Central.

El volumen exportado en Kgs. presentaba la misma tendencia de su valor en ventas, una reducción de $91 \%$ en el período 1978-86; con oscilaciones en la tasa de crecimiento anual que muestran que entre 1979 a 1981 el volumen se había reducido a una tasa promedio de $-24 \%$. Para los afios de 1982 y 1983 las exportaciones habian crecido posilivamente en volumen a $1.8 \%$ y $8.5 \%$ respectivamente.

Pero nuevamente en el año 1984 se presentaba la más alta tasa de decrecimiento del período - $79.3 \%$, el ano 1985 mostro una recuperación importante en el volumen exportado de $238 \%$ con respecto a la drástica caida del ańo anterior, pero no lograndose mantener para 1986 dada la fuerte contracción en los precios en el mercado internacional que llego a alcanzar para esle año, tan solo a 34.54 dólares por quintal.

La tendencia de las exportaciones del algodón, esta ciertamente asociada a las condiciones que presenta el mercado externo en relación a los precios, demanda y oferta del producto. Estas no parecen haber sido las más favorables durante el perlodo, dado que el precio si bien presento variaciones, la tendencia general fue hacia la baja habiendose reducido de 65.29 dólares por quintal oro (grado C1. ANA) en 1978 a 32.54 dólares por quintal en 1986, una contracción del $50 \%$ en el precio internacional.

El mercado mundial presentaba una lendencia al aumento de las exislencias causadas por condiciones climalológicas favorables en palses productores y la incorporación de china como exportador después de 
haber sido tradicionalmente importador de la fibra. El incremento en la producción en algunos paises como Estados Unidos, China, Brasil, Pakistan y otros debido a factores climálicos y al aumento en áreas de producción ha propiciado, conjuntamente al debil crecimiento del consumo una tendencia a la reducción en los precios.

El carácter dependiente de la actividad algodonera del mercado internacional hace del pals esencialmente un "lomador de precios" y por lo tanto altamente fragil y cóndicionado a las oscilaciones que se presentan en el exlerior.

El cuadro No. 16 muestra las modificaciones que a través de los últimos años se ha dado de nuestros principales compradores de algodón; uno de los clientes más imporlanles en la década de los '70 era Japón que absorbia más del $50 \%$ de nuestras exportaciones, para las dos últimas cosechas consideradas este ha desaparecido dentro de la estructura de compradores debido a las facilidades que le brinda un nuevo abastecedor como es China.

De una estructura bastante diversilicada de compradores del algodón del pals (16 países), se ha ido reduciendo el mercado a 364 paises, por otro lado han aparecido en esta estructura nuevos clientes como son

Cuadro No. 16

Ventas de algodón por pals de destlno de cosechas selecclonadas

\begin{tabular}{|c|c|c|c|c|c|c|c|c|}
\hline \multirow{2}{*}{$\begin{array}{l}\text { Palees } \\
\text { Compra- } \\
\text { dores }\end{array}$} & \multicolumn{2}{|c|}{197879} & \multicolumn{2}{|c|}{$1983 / 84$} & \multicolumn{2}{|c|}{$1985 / 86$} & \multicolumn{2}{|c|}{$1986 / 87$} \\
\hline & $\mathbf{Q Q}$ & $\begin{array}{c}\text { Colones } \\
\text { miles }\end{array}$ & $\infty$ & $\begin{array}{c}\text { Colones } \\
\text { miles }\end{array}$ & $\infty$ & $\begin{array}{c}\text { Colones } \\
\text { miles }\end{array}$ & $\infty$ & $\begin{array}{c}\text { Colones } \\
\text { miles }\end{array}$ \\
\hline $\begin{array}{l}\text { Japon } \\
\text { China }\end{array}$ & $\begin{array}{l}865.735 \\
211.623\end{array}$ & $\begin{array}{r}117.298 .9 \\
37.124 .4\end{array}$ & 65.680 & 16.278 .4 & & & & \\
\hline Italia & 80.523 & 15.696. & 3299 & 823.5 & & & & \\
\hline & $\begin{array}{l}88.307 \\
41.846\end{array}$ & $\begin{array}{r}16.339 .7 \\
7.858 .6\end{array}$ & 15.932 & 3.990 .9 & & & & \\
\hline Tailandia & 38.511 & 6.548 .7 & & & & & & \\
\hline Holanda & 23.580 & 4.134 .9 & & & & & & \\
\hline Portugal & 15.078 & $\begin{array}{l}2.837 .1 \\
2.596 .4\end{array}$ & $\begin{array}{l}9.685 \\
2117\end{array}$ & $\begin{array}{r}2.403 .8 \\
5398\end{array}$ & $\begin{array}{r}3.457 \\
0.86\end{array}$ & 362.9 & & \\
\hline Corea & 8.737 & $\begin{array}{l}2.080 .4 \\
1.769 .5\end{array}$ & & & & & & \\
\hline $\begin{array}{l}\text { Belolca } \\
\text { Guatemala }\end{array}$ & & & 6.036 & 1.548 .0 & 5.876 & 1.043 .6 & 5.699 & 1.510 .4 \\
\hline Mexico & & & & & & & 5.025 & 1.155 .9 \\
\hline $\begin{array}{l}\text { Oros } \\
\text { Pendlente }\end{array}$ & 13.375 & 2.182 .1 & 485 & 121.5 & 933 & 277.0 & 1.844 & 424.2 \\
\hline Embarque & 6.802 & 1.113 .6 & 28.732 & 5.601 .0 & 90.255 & 15.496 .1 & 26.630 & 8.683 .9 \\
\hline too & $\begin{array}{r}39.548 \\
1256338\end{array}$ & $\begin{array}{r}6.926 .9 \\
220.929 .8\end{array}$ & $\begin{array}{l}207.418 \\
339.398\end{array}$ & $\begin{array}{l}41.824 .8 \\
77.820\end{array}$ & 179 & $\begin{array}{r}19.7 \\
\end{array}$ & & 19770 \\
\hline & & & 339.388 & 77.152 .0 & 101.688 & 17.337.6 & 39.201 & 11.774 .6 \\
\hline
\end{tabular}


México, Bélgica, Costa Rica y Taiwan. Esta significativa reducción de los países compradores puede estar asociado a la reducción de la producción exportable del algodón, a la competividad que presenta el mercado mundial del algodón y posiblemente a problemas en la comercialización del producto por parte de COPAL.

En general no parecen lodavia presentarse sintomas positivos de gran alcance en el mercado internacional y en las condiciones de producción internas que reviertan la tendencia decreciente de las exportaciones.

El otro componente de la demanda es el consumo interno especialmente de las tábricas de hilados y tejidos. Se considera que "aproximadamente el $17.6 \%$ del total del algodón oro era usado en el mercado inlerno por estas industrias". 21

La industria de hilos y telas, transforma el algodón oro en otros productos que sirven de materia prima o insumos a otras industrias como la induslria del vesluario, cortinas, muebles, etc. ${ }^{22}$

Cuadro No. 17

Ventas de algodón oro al mercado nacional cosechas $1978 / 79$ a 1986/87 (pacas)

\begin{tabular}{|c|c|c|c|c|c|c|c|c|c|}
\hline Coweche & 197870 & 1872900 & 17e0/e1 & 1081/R2 & $1002 / 83$ & 108384 & 1084/85 & $1985 / 86$ & $1898 / 87$ \\
\hline Verrese & 60.537 & 42695 & 38.238 & 25.052 & 43377 & 64.665 & 44.800 & 62153 & 30.534 \\
\hline $\begin{array}{l}\text { Tay de } \\
\text { crocimiento }\end{array}$ & $86 . \theta$ & -329 & -10.2 & .34 .4 & 73.1 & 49.0 & -30.6 & 38.5 & -38.3 \\
\hline
\end{tabular}

- Una paca puede pesar entre 4.99 a 5 CO.

Fuente: Memorias de la COPAL.

El comportamiento de las ventas de algodón a las empresas industriales de textiles del pais ha sido fluctuante, entre las cosechas de 1979/80 a 1981/82 el consumo de la fibra se redujo drásticamente a una lasa promedio por cosecha de $-2.5 \%$, conlracción significaliva ya que la demanda se redujo a cerca del $40 \%$ del consumo de $1978 / 79$.

Los efectos de la crisis socio-política durante los primeros anos de los ' 80 incidieron en esla reducción, ya que se presentaron en estos anos, baja inversión, contracción general de la actividad industrial, fuga de capitales, etc.

El consumo interno presenta recuperación entre los años de 1982 a 1984, mostrando las ventas a la industria textil y otras, tasas de crecimiento positivas. Para 1983 la tasa es de $73.1 \%$ y para $1983 / 84$ de $49 \%$ cierlamente una recuperación significativa.

En los últimos anos el nivel de ventas cae, para 1984/85 la tasa es de - 
- $30.6 \%$ y en $1986 / 87$ de - $36.3 \%$. Solamente para la cosecha $1985 / 86$ las ventas alcanzaron casi el nivel de 1978/79 (62.153 pacas).

La tendencia oscilante de las ventas en el mercado interno hacen dificil prever sobre las ventas futuras, dependerá esencialmente de la reactivación de la actividad industrial y especialmente de la textil el impulso que lome el consumo interno del algodón.

El problema radica en la actualidad que la COPAL para las dos últimas cosechas tiene un déficit de algodón para suplir las necesidades del mercado interno, lo cual a obligado a las empresas textiles a importar, por lo tanto se hace necesario resolver las causas que han provocado el deterioro en la producción algodonera.

\section{Tendenclas de los preclos}

Analizaremos los precios de las exportaciones y los precios de venta del algodón oro en el mercado interno.

Cuadro No. 18

Preclos promedlo del algodón: mercado naclonal.

por paca.

\begin{tabular}{|c|c|c|c|c|c|c|c|c|c|}
\hline Canechn & $107 \mathrm{r} /$ & 187980 & 178001 & $1891 / 82$ & $1000 / 23$ & 100384 & 1884/85 & 1985/86 & $1986 / 87$ \\
\hline Proto & 8840 & 000.5 & 1.0527 & 918.8 & 2003.1 & 1.107 .8 & 1.100 .8 & 1.344 .4 & 1.686 .4 \\
\hline Terideridn & 14.8 & 24 & 15.7 & .221 & 13.8 & 18.7 & -0.6 & 221 & 25.4 \\
\hline
\end{tabular}

1. El precio promedio de la peca de algodón ha sido calculado, dividiendo el total de venas en colones por cada cosecha entre el btal de ventas de algodón en pacas.

Fuenis: Mernorias do la COPAL

Con respecto a los precios de exportación del algodón, cabe sefialar que un análisis delallado se hizo en el apartamenlo correspondiente a las causas que explican el comportmaiento de la producción, por lo tanlo solo nos referimos a los precios de venta en el mercado nacional.

El precio del algodón para venta en el mercado nacional, se fija entre la Cooperallva Algodonera y la Unión de Industrias Textiles (UNITEX), sobre la base de acuerdos adecuados a los intereses de cada gremio.

La Cooperaliva Algodonera debe reservar primero la cantidad requerida para la industria textil tralando de garantizar el suminis|ro adecuado a estas empresas, pero dado que los requerimientos de calidad de la flbra - necesarios a estas industrias- decayó en los últimos años, estas tuvieron que importar en una mayor cuantia.

La tendencia general que presemlan los precios promedios internos de algodón es de un incremenlo de $10 \%$ anual en el período de 1978 a 1987. 
con mayores alzas en las dos últimas cosechas, el incremento de los costos de producción del algodón, así como la política de devaluación que incidio sobre dichos cosios son algunos de los factores incidentes en este mayor crecimienlo de los precios de la fibra.

El precio de estos insumos para la industria textil y de todas aquellas que ulilicen esle componente en su proceso de producción, se deberá considerar a fin de que no incida en una restricción de la demanda de los productos industriales.

\section{Estructura de comerclalización}

La estruclura de comercialización del algodón, se caracteriza por el control que la cooperativa algodonera ejerce sobre las ventas al exterior y al mercado nacional.

La COPAL monopoliza la comercialización de la fibra del algodón, asi como también de algunos de los derivados del algodón (semilla, linters, mola, elc.).

El proceso consiste en que el productor entrega su cosecha de algodón rama a las plantas desmotadoras de algodón, que son propiedad de la COPAL, para su procesamiento y conversión en algodón oro, la

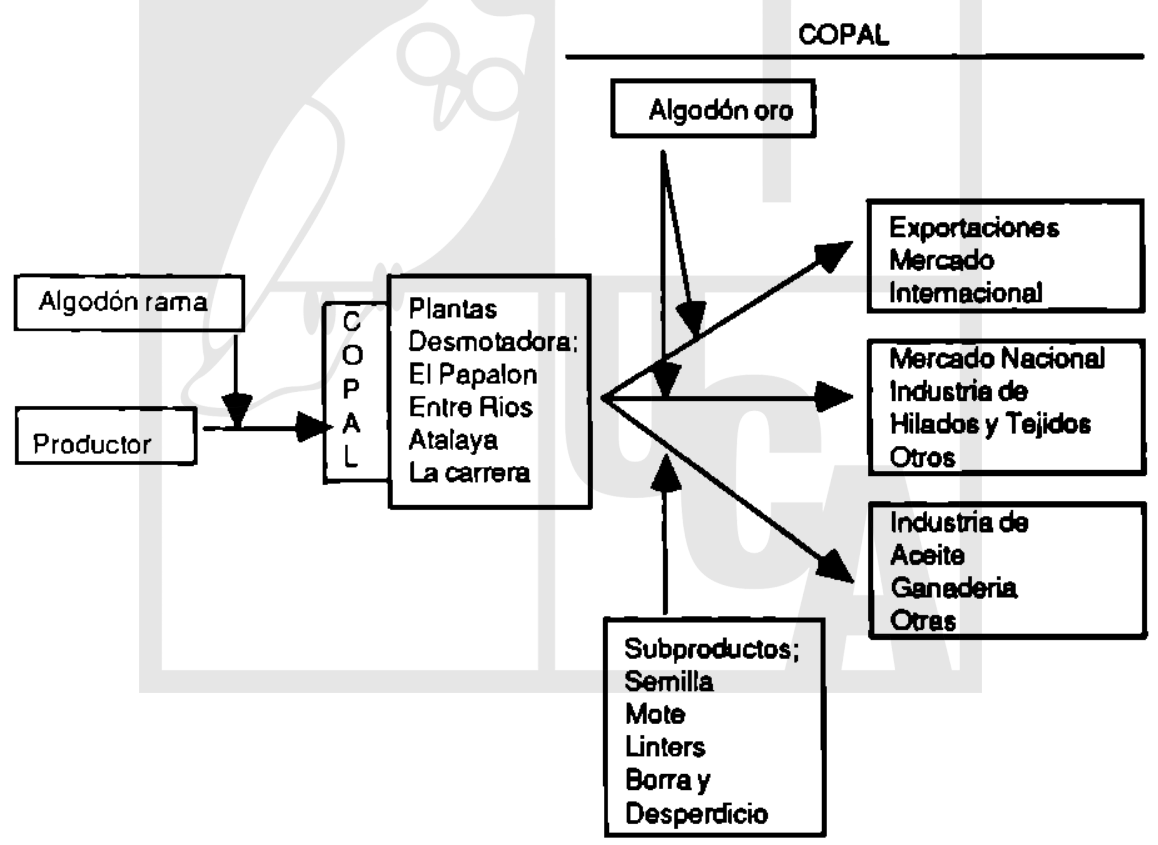

Esquema de comercialización del algodón 
inslitución fija el precio de liquidación al productor y luego vende al mercado externo y al mercado interno.

\section{Estructura de la producclón algodonera}

Otro de los aspectos importantes de la producción algodonera se refiere al lipo de productores, a la forma de lenencia de la tierra y a la lógica de organización de la producción, eslos elementos podrían mostrarnos de alguna manera la situación que enfrentan los productores en la actualidad.

Es necesario sefialar que la reforma agraria desarrollada a partir de 1980 generó cambios en la estructura de propiedad de la tierra, asi como en la adopción de formas cooperativas de producción en la agricultura. Cambios que también se presentaron en el cullivo del algodón y que generaron dislorciones en esta actividad económica, dada la necesidad de adaptación del campesino a las nuevas formas de gestión y organización. A su vez las unidades productoras cooperastivas dedicadas al cultivo del algodón se ven sometidos al conjunlo de lactores que han incidido durante estos anos en la caida de producción algodonera.

\section{Tipo de productores y volumen de producción por unidad económica}

Comenzaremos estudiando la situación del número de productores en relación al tamafio de las explotacioens antes de la reforma agraria.

De acuerdo a la información del cuadro No. 19 asumiremos una clasilicación de las explotaciones algodoneras de acuerdo al tamano de la propiedad en donde se cultiva.

Cuadro No. 19

Algodón número de productores, superflcle sembrada, producción y rendimlento por estrato y total. $1977 / 78$

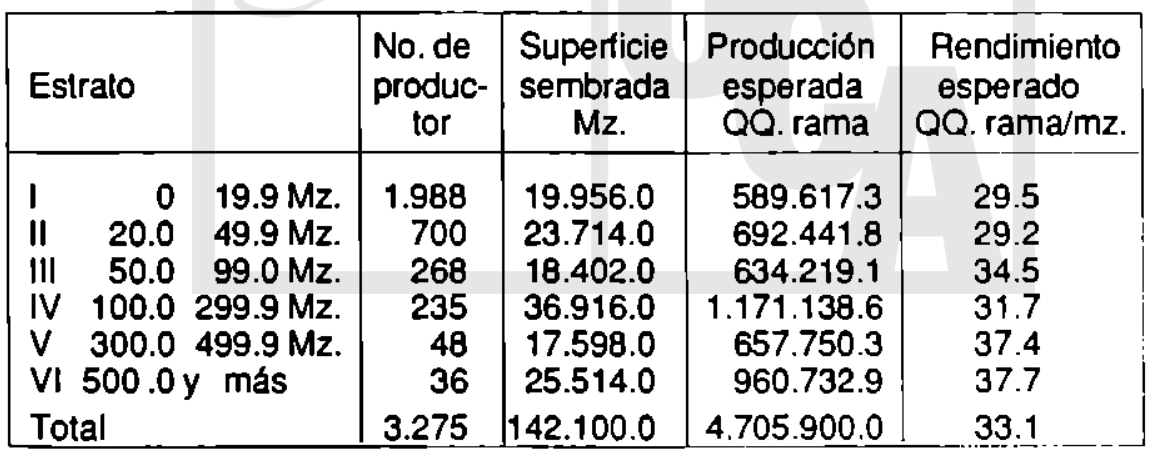

Fuente: Encuesta por muestreo. DGEA. -MAG.- 
Los primeros tres estratos corresponden al concepto de pequenos productores, el estrato IV al de medianos y los estratos $V$ y VI pueden considerarse como grandes explolaciones". 23

En base a esta clasificación mediremos: la cantidad de produclores ubicados en cada estrato comparativamenle; la superficie sembrada y el promedio correspondiente a cada tipo de productor; y los rendimienlos promedios esperados por tipo de explotación.

Un primer aspecto que se identifica es que los pequefios productores son 2956 represenlando el $90 \%$ del lotal de productores y siembran una supericie igual a $62.072 \mathrm{Mz}$. que constituye el $43.6 \%$ de la superticie sembrada y oblienen un rendimiento promedio de 31 qq por maz.

En el otro extremo 84 grandes productores que representan tan solo el $2.5 \%$ del lotal de produclores siembran un área igual a $43.112 \mathrm{mz}$. que absorbe el $30 \%$ de la superticie cultivada de algodón, obteniendo rendimienlos superiores a 37.5 quinlales por manzanas.

Entre estos dos tipos de explotaciones se encuentran 235 produclores o sea el $7.1 \%$ del tolal de productores, que consiguen un rendimiento de $31.7 q 9$ por maz. en el $26 \%$ de la superficie cultivada que es de $36.916 \mathrm{mz}$.

Un aspecto relevante es que denlro de las pequenas explotaciones, el estrato de 0-19.9 mz. integra el 60.\% de los productores y estos lienen rendimienlos inferiores a los 30 qq por maz., sembrando tan solo el $14 \%$ de la superticie cultivada. Estos productores en promedio cada uno lendría acceso a 10 manzanas para el cultivo del algodón.

En promedio los grandes productores ubicados en el eslrato de 500 y más manzanas, lendrian 708 manzanas cada uno para cultivar algodón, - sea más de 70 veces la de los pequeños productores del estralo I.

Cuadro No. 20

Algodón número de productores, superflcle sembrada, producción y rendimlento por reglón y total. 1977/78

\begin{tabular}{|c|c|r|r|c|}
\hline Región & $\begin{array}{c}\text { No de } \\
\text { productores }\end{array}$ & $\begin{array}{c}\text { Superficie } \\
\text { sembrada } \\
\text { mz. }\end{array}$ & $\begin{array}{c}\text { Producción } \\
\text { esperada } \\
\text { qq. rama }\end{array}$ & $\begin{array}{c}\text { Rendimiento } \\
\text { esperado } \\
\text { qq. rama/mz. }\end{array}$ \\
\hline I & 35 & 5.651 .0 & 192.661 .5 & 34.1 \\
II & 20 & 4.661 .0 & 182.303 .8 & 39.1 \\
III & 396 & 40.735 .0 & 1.397 .072 .8 & 34.3 \\
IV & 2.824 & 91.053 .0 & 2.933 .861 .9 & 32.2 \\
Tolal & 3.275 & 142.100 .0 & 4.705 .900 .0 & 33.1 \\
\hline
\end{tabular}

Fuenle:

506 
La distribución de los productores de algodón por región, muestra que el $\mathbf{8 6 \%}$ (2824) de los productores se ubican en la región IV. cullivando el $64 \%$ de la superficie sembrada en el año 1977/78, proporcionando el $62 \%$ de la producción y obteniendo los menores rendimientos comparativamente a las otras regiones ( $32.2 \mathrm{qq} \mathrm{rama} / \mathrm{mz}$.).

En la región II se ubican tan sólo 20 productores que representan menos del $1 \%$ del tolal, que siembran el $32.2 \%$ de la supericie cultivada y proporcionan el $3.8 \%$ de la producción esperada, con el mayor rendimienlo por manzana de (39.1 qq rama/ $\mathrm{mz}$.).

La región III es la segunda en cuanto a la mayor cantidad de productores; estos represenlan el $12 \%$ del total, el rendimiento esperado en esta región es de $34.3 \mathrm{qq}$. rama/mz, también la segunda en relación a las olras regiones, cultivan el $28.6 \%$ de la superficie y esperan producir el $29 \%$ del tolal de la cosecha $1977 / 78$.

Por úlimo la región I aglutina a 35 productores (1\%), que producen el $4 \%$ del tolal esperado en una superticie sembrada del $3.9 \%$ y con un rendimiento promedio de $34.1 \mathrm{qq} / \mathrm{mz}$.

El cuadro No. 21 permite apreciar algunas características importantes de los produclores según tamaño de la explolación y la región donde estan ubicados. Anteriormente señalamos que la mayor cantidad de productores estan ubicados en la región IV, de las cuales el $1.3 \%$ son grandes productores que cullivan el $21.8 \%$ del área de la región dedicada al algodón, con un tamaño promedio de explotaciones de 522 manzanas. En esta misma región el $94 \%$ son pequefios produclores, que con un lamaño promedio de 18 manzanas por produclor cubren una superticie sembrada de algodón del 53\% del total de la región.

En la region III la segunda más importante en área sembrada y número de produclores, se encuentra un $8.8 \%$ (35) de grandes produclores que cultivan el $41.7 \%$ de la lierra dedicada al algodón y lienen un tamaño promedio de explolación de 486 manazanas. En el otro exlremo se encuentran $68 \%$ de productores considerados pequefios que siembran el $30 \%$ de la tierra con un lamano promedio de explotaciones de 45 manzanas, ciertamente superior en 2.5 veces a las de la región IV.

Las regiones I y II tienen la menor proporción de produclores y área sembrada de algodón, pero los grandes productores que son 5 y 6 para cada una de estas regiones cultivan en un tamafio promedio de explotación superior a las $\mathbf{5 4 5}$ manzanas, mientras que los más pequenos produclores cultivan en tierras de tamaño promedio de 40 y 50 manzanas respectivamente para cada región.

La mayor cantidad de medianos productores se encuentran en las regiones IV y III con $54 \%$ y $37 \%$ respectivamenle del lolal de produclores 
Cuadro No. 21

Número de productores, superflcle sembrada, total por reglón y estrato $1977 / 78$

\begin{tabular}{|c|c|c|c|c|c|c|c|c|c|c|}
\hline \multirow[b]{2}{*}{ Estratos } & \multicolumn{2}{|c|}{ Total } & \multicolumn{2}{|c|}{ Región I } & \multicolumn{2}{|c|}{ Región II } & \multicolumn{2}{|c|}{ Región III } & \multicolumn{2}{|c|}{ Región IV } \\
\hline & $\begin{array}{l}\text { No. de } \\
\text { Produc- } \\
\text { tores }\end{array}$ & $\begin{array}{l}\text { Superficie } \\
\text { sembrada } \\
\text { Mz. }\end{array}$ & $\begin{array}{l}\text { No. de } \\
\text { produc- } \\
\text { tores }\end{array}$ & $\begin{array}{l}\text { Superficie } \\
\text { sembrada } \\
\text { Mz. }\end{array}$ & $\begin{array}{l}\text { No. de } \\
\text { produc- } \\
\text { tores. }\end{array}$ & $\begin{array}{l}\text { Superficie } \\
\text { sembrada } \\
\text { Mz. }\end{array}$ & $\begin{array}{l}\text { No. de } \\
\text { produc- } \\
\text { tores. }\end{array}$ & $\begin{array}{l}\text { Superficie } \\
\text { sembrada } \\
\text { Mz. }\end{array}$ & $\begin{array}{l}\text { Node } \\
\text { produc- } \\
\text { tores. }\end{array}$ & $\begin{array}{l}\text { Superticie } \\
\text { sembrada } \\
\text { Mz. }\end{array}$ \\
\hline $0 \quad 19.9 \mathrm{Mz}$ & 1.988 & 19.956 .0 & 4 & 32.0 & 1 & 9.0 & 74 & 966.0 & 1.909 & 16.949 .0 \\
\hline $20.0 \quad 49.9 \mathrm{Mz}$ & 700 & 23.714 .0 & 3 & 95.0 & - & - & 147 & 6.740 .0 & 550 & 16.879 .0 \\
\hline $50.0 \quad 99.9 \mathrm{Mz}$ & 268 & 18.402 .0 & $\mathbf{B}$ & 474.0 & 9 & 563.0 & 51 & 4.536 .0 & 200 & 12.829 .0 \\
\hline $100.0299 .9 \mathrm{Mz}$ & 235 & 36.916 .0 & 15 & 2.119 .0 & 4 & 804.0 & 89 & 11.468 .0 & 127 & 22.525 .0 \\
\hline $300.0499 .9 \mathrm{Mz}$ & 48 & 17.598 .0 & 2 & 861.0 & 3 & 1.285 .0 & 19 & 7.494 .0 & 24 & 7.958 .0 \\
\hline 500. y más & 36 & 25.514 .0 & 0 & 2.070 .0 & 3 & 2.000 .0 & 16 & 9.531 .0 & 14 & 11.913 .0 \\
\hline Total & 3.275 & 142.100 .0 & 35 & 5.651 .0 & 20 & 4.661 .0 & 396 & 40.735 .0 & 2.824 & 91.053 .0 \\
\hline
\end{tabular}

Fuente: Enavesta por Muestreo. D.G.E.A. MAG. 
de este tipo; los productores de la región III cultivan el $31 \%$ del área sembrada y las de la región IV el $61 \%$ del tolal de la superticie dedicada al algodón.

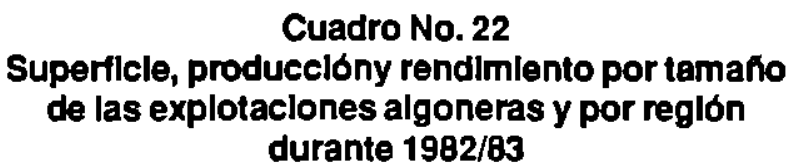

Superflcle: Mlles de manzanas

Producclón: Miles de QO. rama

Rendlmiento: QQ. rama/mz.

\begin{tabular}{|c|c|c|c|c|c|}
\hline \multirow[b]{2}{*}{ Estratos } & \multicolumn{5}{|c|}{ Pegiones } \\
\hline & Tolal & Occidental & Central & Paracent. & Oriental \\
\hline \multirow{6}{*}{$\begin{array}{l}\text { Superlicie total } \\
\text { Producción total } \\
\text { Rendimiento nacional } \\
\text { I. (0.01.19.99 Mz.) } \\
\text { Superticie } \\
\text { Producción } \\
\text { Rendimiento } \\
\text { II. }(20-49.99 \mathrm{Mz} \text {.) }\end{array}$} & 69.80 & 1.61 & 2.75 & 20.73 & 44.71 \\
\hline & 2.370 .0 & 55.09 & 110.28 & 722.55 & 1.482 .08 \\
\hline & 33.90 & 34.30 & 40.10 & 34.90 & 33.10 \\
\hline & 5.22 & 一 & 0.004 & 0.16 & 5.06 \\
\hline & 165.27 & - & 0.14 & 5.31 & 159.67 \\
\hline & 31.66 & & 34.95 & 33.19 & 31.55 \\
\hline \multirow{3}{*}{$\begin{array}{l}\text { Superficie } \\
\text { Producción } \\
\text { Rendimiento } \\
\text { III. }(50-99.99 \mathrm{Mz} \text {.) }\end{array}$} & 7.99 & 0.7 & 0.06 & 0.77 & 7.08 \\
\hline & 253.11 & 2.38 & 2.55 & 24.59 & 223.41 \\
\hline & 32.45 & 34.00 & 42.50 & 31.94 & 31.56 \\
\hline \multirow{3}{*}{$\begin{array}{l}\text { Superficie } \\
\text { Producción } \\
\text { Pendimiento } \\
\text { IV. }(100-299.99 \mathrm{Mz} \text {.) }\end{array}$} & 8.14 & 0.07 & 0.58 & 1.51 & 5.88 \\
\hline & 270.99 & 2.45 & 21.54 & 49.17 & 197.75 \\
\hline & 33.29 & 35.00 & 37.13 & 32.56 & 33.63 \\
\hline \multirow{3}{*}{$\begin{array}{ll} & \text { Superticie } \\
\text { Producción } & \\
\text { Rendimiento } \\
\text { V. } & (300-499.99 \mathrm{Mz} .)\end{array}$} & 19.67 & 0.39 & 0.31 & 7.30 & 10.67 \\
\hline & 542.25 & 12.11 & 12.05 & 259.68 & 308.56 \\
\hline & 31.72 & 31.05 & 38.87 & 35.57 & 28.92 \\
\hline \multirow{4}{*}{$\begin{array}{l}\text { Superticie } \\
\text { Producción } \\
\text { Pendimiento } \\
\text { IV. ( } 500 \text { y más } \mathrm{Mz} \text {.) }\end{array}$} & 12.81 & 1.08 & 0.81 & 4.49 & 6.44 \\
\hline & 457.00 & 38.13 & 31.95 & 160.47 & 226.57 \\
\hline & 35.68 & 35.30 & 39.44 & 35.74 & 35.18 \\
\hline & & & & & \\
\hline \multirow{3}{*}{$\begin{array}{l}\text { Superficie } \\
\text { Producción } \\
\text { Rendimiento }\end{array}$} & 16.65 & - & 0.98 & 6.39 & 9.47 \\
\hline & 627.59 & - & 42.05 & 223.36 & 362.27 \\
\hline & 37.69 & - & 42.90 & 34.95 & 38.25 \\
\hline
\end{tabular}

Fuente: Encuesta de Algodón 1982, D.G.E.A. -MAG. 
En general las características que muestran los cuadros anteriores son que existe una alta concentración de superficie sembrada de algodó en las distintas regiones, por grandes productores los cuales consituyen una pequefáa proporción del lolal; en cambio una gran cantidad de pequefios productores se concentran en las regiones III y IV con un bajo rendimieto de producción, aunque el tamańo promedio de las explolaciones va aumentando en la medida que la región dedicada al algodón es menos importante,

Los productores medianos son una parte importante en las regiones donde se cultivan más algodón (III y V) y consliluyen también con una parte importante de la producción en su respectiva región.

Para la cosecha 1982/83, el proceso de reforma agraria ha sido ya implementada, aunque no se tiene el número de productores por lamafio de explolación ni por región, consideramos que dicho proceso ha modificado las formas de propiedad de la tierra y organización de la producción, pero no la lógica económica como opera cada tipo de explotación.

Para evidenciar esto se debe considerar las características ya explicadas del período anterior (1977/78), es decir para la cosecha 1982/83 los grandes productores generaban el $49 \%$ de la producción y cultivaban el $42 \%$ del área sembrada con un allo rendimiento de $36.6 \mathrm{qq} / \mathrm{mz}$. de algodón.

En cambio los pequenos productores generaban un $29 \%$ de la producción en un área de $30 \%$ del tolal de la superficie cultivada, con un rendimiento promedio $32.4 \mathrm{qq} / \mathrm{mz}$.

Los medianos productores con un rendimiento de $31.7 \mathrm{qq} / \mathrm{mz}$. producian el $22 \%$ del algodón del período en una superticie cultivada de $28 \%$ del total sembrado.

Analizando por región, la zona oriental y paracentral contribuyen con la mayor proporción de la producción del $68 \%$ del total, en una superficie cultivada de $93 \%$ de toda el área dedicada al algodón. Asimismo los grandes productores de estas regiones culivaron más del $38 \%$ de la superticie sembrada y produjeron más del $50 \%$ del total de la producción, con los rendimienlos más altos 33 qq. rama por manzana.

Los pequefios productores de algodón de las regiones oriental y paracentral produjeron el $27 \%$ de todo el algodón para la cosecha $82 / 83$ con un rendimiento de $32 \mathrm{qq} / \mathrm{mz}$. sembrando una superticie igual al $28 \%$ del total de ese periodo.

Estos elemenlos considerados nos evidencian el hecho que la lógica de producción se mantiene aún después de la reforma agraria, en relación a que los altos rendimientos, mayor área cullivada y producción se 
concentra en los grandes productores; los pequenos productores presentan un bajo rendimiento en el cullivo son una gran cantidad y absorben una parte importante del área cultivada.

Ciertamente ahora el cultivo del algodón puede hacerse en grandes unidades producloras cooperativas ubicadas en las zonas o regiones de mayor imporlancia para el cultivo del algodón.

\section{La tenencia de la tlerra en el cultlvo del algodón}

La estructura del régimen de tenencia nos muestra tres formas en los cuales se aglutinan los productores de algodón, los que trabajan en forma de propietarios, los que alquilan la tierra y los que combinan ambas formas de lenencia.

Los que operan bajo la forma de lenencia de propietarios han ido disminuyendo duranle las distintas cosechas, para la cosecha 1979/80 eran 1.299 y para la cosecha $1985 / 86$ se habian reducido en un $81 \%$, es decir a 246 propietarios. Eslos propietarios constituian la forma de tenencia más importante enlre 1979 y 1987, representando más del 54\% de los productores en estos anos, para los úllimos años estos son interiores al $55 \%$ de los productores, es decir son menos importantes dentro de la esiructura de tenencia por productores.

La superficie sembrada de algodón en forma de propiedad se ha ido reduciendo al igual que los productores que funcionan bajo esta forma de tenencia. Para la cosecha 1979/80 se habia sembrado 71.735 manzanas y en la cosecha 1985/86 se había reducido en 4.3 veces llegando solo a 16.370 manzanas. La contribución de esta forma de lenencia en la superticie cultivada ha ido disminuyendo a lo largo del período 1979/86, presentando su mayor aporte de 1979 a 1982 que superaba el $50 \%$ de la superticie sembrada y disminuyendo a un promedio de $37 \%$ para las últimas cosechas consideradas.

En cuanto a la lorma de tenencia alquilada, esta también se ha vislo reducida tanto en el número de productores como en la superticie cultivada. Entre la cosecha 1979/80 y la cosecha 1985/86 el número de productores que alquilaba tierras se redujo en 3.6 veces y la superticie que cultivaban en 3.4 veces.

Los produclores algodoneros que alquilan lierras constiluyen una forma importante de lenencia, si bien eslo ha ido variando a través de las cosechas consideradas; en los últimos afios (1984/86) conlorman en promedio el $50 \%$ de los productores. Asimismo su aporte en términos de superficie cultivada ha sido igual o superior a la de los propietarios en los últimos anos, sembrando en promedio el $40 \%$ de la superticie dedicada al algodón enlre 1984 a 1986. 


\section{Cuadro No. 23}

Algodon: número de productores y superticle sembrada por tenencla de la tlerra según cosechas.

\begin{tabular}{|l|l|c|c|r|c|c|c|c|}
\hline & \multicolumn{4}{|c|}{ Productores } & \multicolumn{4}{c|}{ Superficie sembrada (Mz.) } \\
\cline { 2 - 8 } Cosecha & Propia & Alquil. & Otra' & Total & Propia & Alquil. & Ora & Total \\
\hline $1979 / 80$ & 1299 & 1093 & - & 2.392 & 71.735 & 49.065 & - & 120.800 \\
$1980 / 81$ & 1211 & 530 & 62 & 1803 & 43.818 & 18.683 & 20.699 & 83.200 \\
$1981 / 82$ & 1099 & 246 & 73 & 1418 & 44.442 & 13.241 & 17.317 & 75.000 \\
$1982 / 83$ & 763 & 477 & 69 & 1.309 & 23.294 & 22.949 & 23.558 & 69.800 \\
$1984 / 85$ & 377 & 440 & 99 & 916 & 20.055 & 22.330 & 10.805 & 53.300 \\
$1985 / 86$ & 246 & 300 & 43 & 589 & 16.370 & 14.595 & 7.935 & 38.000 \\
\hline
\end{tabular}

1. Se refiere a superficie que en parte es propia y en parte alquilacta.

Fuento: Encuesta sobre el eulivo del algodón, distintas cosechas. División de Estadisticas Agropecuarias, D.G.E.A., MAG.

Cuadro No. 24

Algodon: Estructura porcentual de número de productores y superflcle sembrada por tenencla de la llerra según cosechas.

\begin{tabular}{|l|l|c|c|c|c|c|c|c|}
\hline & \multicolumn{4}{|c|}{ Productores } & \multicolumn{4}{c|}{ Superficie sembrada (Mz.) } \\
\cline { 2 - 8 } Cosecha & Propia & Alquil. & Otra & Total & Propia & Alquil. & Otra & Total \\
\hline $1979 / 80$ & .54 & 46 & - & 100.0 & 59 & 41 & - & 100.0 \\
$1980 / 91$ & 67 & 30 & 3 & 100.0 & 53 & 22 & 25 & 100.0 \\
$1981 / 82$ & 77 & 17 & 6 & 100.0 & 59 & 18 & 23 & 100.0 \\
$1982 / 83$ & 58 & 36 & 6 & 100.0 & 33 & 33 & 34 & 100.0 \\
$1984 / 85$ & 41 & 48 & 11 & 100.0 & 38 & 42 & 20 & 100.0 \\
$1985 / 86$ & 42 & 51 & 7 & 100.0 & 42 & 37 & 21 & 100.0 \\
\hline
\end{tabular}

Fuento: En base al euadro No. 23.

La forma de lenencia combinada (propiedad y alquilada) si bien no es relevante en relación al número de productores ya que no supera el $11 \%$ deniro de esla estruclura y, en promedio representan solamenle el $5.5 \%$ para cada cosecha considerada. Su aporte es significalivo en términos de la superticie cultivada ya que estos siembran más del $20 \%$ de la superticie algodonera.

Podemos considerar que tanto el número de productores y la superficie cullivada por forma de tenencia de la tierra ha ido disminuyendo considerablemente debido a la fuerte contracción de la producción algodonera en los akos 'B0, fenómeno relacionado a un conjunlo de factores antes explicados. 
Por otra parte la relevancia que cobran las formas de tenencia alquilada de producción puede estar asociada a las lacilidades que el sistema financiero brinda a este tipo de productores y al menor riesgo económico que signilicaria operar en forma alquilada que en propiedad.

Un aspecto que no se puede percibir a través de la información es el impacto que la reforma agraria ha tenido en las formas de tenencia ya que no se especílica el carácter de propietario sea este privado o cooperatizado.

\section{Formas de organlzaclón de la producción}

En El Salvador a partir de 1980 con el decreto de reforma agraria en su fase I, se impulsan nuevas formas de organización de la producción en la agricultura, especialmente formas asociativas de producción (Cooperativas) que debido a la expropiación de tierras a propietarios privados que tenian exlensiones mayores a las $\mathbf{5 0 0}$ hectáreas pasan estas tierras a contro de los campesinos y a las inslituciones gubernamentales relacionadas a este proceso.

Consideraremos por lo tanto dos formas de organización de la producción en el cullivo del algodón, por un lado las privadas (alquilada o en propiedad) que constituyen el sector no reformado y por otro lado las propiedades de las cooperativas que sería el sector reformado.

Cada uno de estos tiene una racionalidad particular, y por to tanto se organizan en torno a ella, la organización privada de producción buscaría la rentabilidad esencial del cultivo en función del interés individual, en cambio las formas de organización asociativas buscarian también la renlabilidad pero en función de los beneficios colectivos a lograr.

Bajo estas consideraciones analicemos cual ha sido la participación de estos dos seclores en la actividad algodonera.

Partiendo del hecho que la actividad algodonera se ha reducido tanto en superticie y producción, vemos que el sector no reformado -para las distinlas cosechas consideradas- ha cultivado en promedio el $54 \%$ de la superticie dedicada al algodón y ha generado el $57 \%$ de la producción algodonera con un rendimiento promedio de 31.2 qq. rama por manzana.

En cambio el sector reformado ha cullivado en promedio el $46 \%$ de la superticie sembrada y producido el $43 \%$ del lotal de la producción algodonera con un rendimiento promedio de 28.8 qq rama por manzana, ciertamente menor que el rendimiento del sector no reformado. "Para la cosecha 1982/83 el sector relormado participó en el cultivo del algodón con 67 cooperalivas sembrando un lolal de 23.395.84 manzanas."24

Mientras el sector no reformado disminuyó su participación en la superficie sembrada y la producción del algodón el sector reformado ha 
Cuadro No. 25

Algodón: superficle, producclón y rendimlento por sector según cosechas

\begin{tabular}{|c|c|c|c|c|c|c|c|c|c|}
\hline \multirow[b]{2}{*}{ Cosectia } & \multicolumn{3}{|c|}{ Sector no relormado } & \multicolumn{3}{|c|}{ Sector reformado } & \multicolumn{3}{|c|}{ Consolidado } \\
\hline & $\begin{array}{l}\text { Superficie } \\
\text { Mz. }\end{array}$ & $\begin{array}{l}\text { Rama } \\
\text { OOs. }\end{array}$ & $\begin{array}{l}\text { Rendimiento } \\
\mathrm{QOMMz} \text {. }\end{array}$ & $\begin{array}{l}\text { Superficie } \\
\text { Mz. }\end{array}$ & $\begin{array}{l}\text { Pama } \\
\text { OOs. }\end{array}$ & $\begin{array}{c}\text { Rendimiento } \\
\mathrm{OOMMz}\end{array}$ & $\begin{array}{l}\text { Superficie } \\
\text { Mz. }\end{array}$ & $\begin{array}{l}\text { Rama } \\
\text { OQs. }\end{array}$ & $\begin{array}{c}\text { Rendimiento } \\
\mathrm{OOMMz} \text {. }\end{array}$ \\
\hline $1982 / 83$ & 45.594 .0 & 1.384 .513 .1 & 32.50 & 28.686 .0 & 923.802 .1 & 32.20 & 71.280 & 2.308 .315 .2 & 32.28 \\
\hline $1983 / 94$ & 31.463 .0 & 986.416 .6 & 31.35 & 22.960 & 704.527 .6 & 30.69 & 54.423 .0 & 1.690 .944 .2 & 31.07 \\
\hline $1985 / 86$ & 19.753 .5 & 575.668 .3 & $\tilde{n} 29.14$ & 19.578 & 464.544 .2 & 23.73 & 39.331 .5 & 1.040 .212 .5 & 26.45 \\
\hline $1986 / / 87$ & 10.207 .7 & 324.918 .7 & 31.83 & 9.442 .5 & 271.858 .5 & 28.79 & 19.650 .2 & 596.777 .2 & 30.37 \\
\hline
\end{tabular}

Fuente : Memorias de la COPAL 
Cuadro No. 26

Algodón: Superflcle y producclon rama por sector según cosecha

(Estructura porcentual)

\begin{tabular}{|l|c|c|c|c|c|c|}
\hline \multirow{2}{*}{ Cosecha } & \multicolumn{3}{|c|}{ Superficie } & \multicolumn{3}{c|}{ Producción rame } \\
\cline { 2 - 7 } & $\begin{array}{l}\text { Sector } \\
\text { No Relorm. }\end{array}$ & $\begin{array}{c}\text { Sector } \\
\text { Retomado }\end{array}$ & $\begin{array}{c}\text { Consoli- } \\
\text { dado }\end{array}$ & $\begin{array}{l}\text { Sector } \\
\text { No Ref. }\end{array}$ & $\begin{array}{c}\text { Sector } \\
\text { Relormado }\end{array}$ & Consolidado \\
\hline $1982 / 83$ & 59.7 & 40.3 & 100.0 & 60.0 & 40.0 & 100.0 \\
$1983 / 84$ & 57.8 & 42.2 & 100.0 & 58.3 & 41.7 & 100.0 \\
$1985 / 86$ & 50.2 & 49.8 & 100.0 & 55.3 & 44.7 & 100.0 \\
$1986 / 87$ & 52.0 & 48.0 & 100.0 & 54.4 & 45.6 & 100.0 \\
\hline
\end{tabular}

Fuente: Elaborado en base al cuadro No. 25.

ido aumentando dicha participación (ver cuadro E. 8). Eslo puede deberse a la baja renlabilidad del cullivo lo cual incide sobre las expectalivas de mayor inversión de los productores privados y a que las cooperativas han recibido flujos importantes de financiamiento y ayuda a lo largo de eslos años.

Estas dos lormas de organización de la producción son las que prevalecen en la actualidad en la actividad algodonera.

\section{Intento de acercamlento a la sltuación de los productores de algodón}

El problema de las condiciones de vida del productor dedicado a la actividad algodonera es compleja, debido a que requiere un esludio puntual del lipo y lamano de la explotación, región donde se ubica, condiciones agroecológicas en la cual esla su unidad producliva, coslos de producción, gastos en consumo de bienes y servicios, etc.

Se tratara de hacer un acercamiento a la siluación del productor diferenciandolos p r tamano de la explotación y suponiendo que el costo de producción es cubierlo en su tolalidad por los ingresos oblenidos y hay un margen de ganancia del $25 \%$.

Ciertamente habrá que recordar que los costos de producción por manzana para la cosecha $1977 / 78$ fueron de $₫ 2.161 .2$ y para la cosecha 1982/83 3.397.4; costos superiores a los ingresos promedios oblenidos por los distintos tipos de produclores en cada cosecha, lo cual nos llevaria a la conclusión que este cultivo no es nada rentable.

Es necesario por to tanto lener "en cuenta que una buena parte de cullivadores de algodón son propietarios de la tierra y además aportan su trabajo junlo con algunos miembros de la familia, por lo cuál, los costos como renta de la tierra, cierla parte de los salarios y otros elementos de costos no conslituyen egresos en electivo".25 


\section{Cuadro No. 27}

Algodón: Ingresos obtenidos y ganancias promedio supuesta por productor, según tamafíos dela explotación. Cosecha $1977 / 78$ y 1982/83

\begin{tabular}{|c|c|c|c|c|c|c|c|c|c|c|c|c|}
\hline $\begin{array}{l}\text { Estrato por } \\
\text { manzanas }\end{array}$ & \multicolumn{2}{|c|}{$\begin{array}{l}\text { Promedio manza- } \\
\text { na culivada }\end{array}$} & \multicolumn{2}{|c|}{$\begin{array}{l}\text { Rendimiento } \\
\text { promedio por Mr. }\end{array}$} & \multicolumn{2}{|c|}{$\begin{array}{l}\text { Precio promedio } \\
\text { QQ. rama }\end{array}$} & \multicolumn{2}{|c|}{$\begin{array}{l}\text { Ingreso promedio } \\
\text { por manzana }\end{array}$} & \multicolumn{2}{|c|}{$\begin{array}{l}\text { Ingreoso lotal } \\
\text { oblenido }\end{array}$} & \multicolumn{2}{|c|}{$\begin{array}{c}\text { Ganancia del } \\
25 \%\end{array}$} \\
\hline & $1977 \pi 8$ & $1982 / 83$ & $1977 \pi 78$ & $1982 / 83$ & $1977 \pi 8$ & $1982 / 83$ & 197778 & $1982 / 83$ & 197778 & $1982 / 83$ & $1977 / 78$ & $1982 / 83$ \\
\hline $0-19.9$ & 10.0 & 10.0 & 29.5 & 31.66 & 56.29 & 76.62 & 1.660 .5 & 2.425 .7 & 16.605 & 24.257 & 4.151 .2 & 6.064 .2 \\
\hline $20-49.9$ & 30.0 & 30.0 & 29.2 & 32.45 & 56.29 & 76.62 & 1.643 .6 & 2.486 .3 & 49.300 & 74.599 & 12.327 & 18.647 .2 \\
\hline $50-99.9$ & 75.0 & 75.0 & 34.5 & 33.29 & 56.29 & 76.62 & 1.942 .0 & 2.550 .6 & 145.650 & 191.295 & 36.412 .5 & 47.823 .7 \\
\hline IV $100-299.9$ & 200.0 & 200.0 & 31.7 & 31.72 & 56.29 & 76.62 & 1.784 .3 & 2.430 .3 & 356.860 & 486.060 & 89215 & 121.515 .0 \\
\hline V $300-499.9$ & 350.0 & 350.0 & 37.4 & 35.68 & 56.29 & 76.62 & 2.105 .2 & 2.733 .8 & 736.820 & 956.830 & 184205 & 239.207 .5 \\
\hline VI 500 y mas & 500.0 & 500.0 & 37.7 & 37.69 & 56.29 & 76.62 & 2.122 .1 & 2.887 .8 & 1.061 .050 & 1.443 .900 & 265.262 .5 & 360.975 .0 \\
\hline
\end{tabular}

1. Suponemos tamaños promedios por estralo.

2. Rendimientos en base a datos cuadro E. 1 y E. 4.

3. Precios promedios por quintal rama según COPAL

4. El rencimiento promedio por precio.

5. El promedio de manzanas cultivadas por ingreso promedio por manzana.

6. Bajo el supuesto de $25 \%$ de ganancia, los ingresos del productor por cosecha. Se deduce que se paga el costo de producción. Fuente: En base a cuadros anteriores y Memorias de la COPAL. 
Se puede agregar además "que muchos agricuthores oblienen rendimientos mayores de 38 quintales por manzana y además el tamaño de las explotaciones les permite realizar economías de escala."26

Bajo eslas consideraciones en el cuadro No. 9 podemos apreciar, que son los pequehos productores los que más bajos ingresos promedios por manzana obtendrían y que en la medida que el tamaño de la explotación aumente los ingresos serlan mayores, son precisamenle las pequefias unidades productoras las que menor rendimiento por manzana presen$\tan$.

La ganancia obtenida por el pequeno produclor dedicado al cultivo del algodón en $10 \mathrm{Mz}$. de tierra, le signilicarla un ingreso mensual promedio de $₫ 345$ en el ano 1978 y de $₫ 505$ para 1983, cierlamenle muy poco dada las condiciones de inflación y costo de la canasta básica para cada uno de estos anos.

En el otro extremo los grandes productores que cultivan 500 manzanas de algodón podrían tener un ingreso mensual promedio de $\$ 22.100$ en 1978 y de $\$ 30.000$ en 1983 . Es decir a un gran productor le bastarla una rentabilidad de $5 \%$ en el cultivo para obtener ingresos superiores a los 4.00066 .000 colones mensuales en los años senalados. Esto significaria que los estralos de lamano mediano y grandes explolaciones podrían obtener ingresos que le garantizan el adecuado acceso a los bienes de consumo necesarios.

Habrá que hacer referencia que en el caso de las cooperativas de la relorma agraria, dado el carácler asociativo de la producción, esle supondria un reparto equilativo de los beneficios obtenidos de la producción entre los socios, lo cual disminuiria el ingreso por familia pero propiciaria mejoras en condiciones de vida a un mayor contingente de población.

\section{El Impacto de la crisis algodonera en la economía}

\section{El sector algodonero y el producto territorlal bruto}

La actividad algodonera ha sido considerada normalmente importante en términos de su contribución al producto sectorial agropecuario como al producto nacional.

Esla actividad ha contribuido en promedio para el periodo 1978 a 1985 con el $1.6 \%$ al Producto Terrilorial Bruto y con un $9.5 \%$ al valor agregado del sector agropecuario. Su relevancia por lo tanto dentro de ambas estrucluras es significativa tratandose de un solo producto.

A través del periodo se puede notar que su participación ha ido disminuyendo, aspeclo relacionado a los problemas que enlrenta este cultivo durante este tiempo y especialmente a la drástica caida de la superficie cultivada. 
Su participación se redujo de $2.3 \%$ en la generación del produclo territorial bruto de 1978 a $0.9 \%$ para 1985 . En relación al producto del seclor agropecuario en 1978 el algodón había contribuido con el $14.6 \%$ del valor agregado de éste sector y para 1985 se habia reducido su participación a $5.5 \%$. Reducciones significativas que tendrá implicaciones sobre el funcionamiento de otras actividades económicas relacionadas con la producción de algodón y el requerimiento de este como insumo.

Cuadro No. 28

Particlpación del sector algodón en el producto territorlal bruto y el valor agregado del sector agropecuarlo

1978-1985 (\%)

(Preclos corrientes y constantes de 1962)

\begin{tabular}{|l|r|r|r|r|r|r|r|r|r|}
\hline Indicadores & 1978 & 1979 & 1980 & 1981 & 1982 & 1983 & 1984 & 1985 & $\begin{array}{c}\text { Promedio } \\
\text { periodo }\end{array}$ \\
\hline $\begin{array}{l}\text { Sector algodón } \\
\text { + PTB p. corr. } \\
\text { Seclor Algodón } \\
\text { + PTB p. const. }\end{array}$ & 1.98 & 1.76 & 1.76 & 1.32 & 0.91 & 1.08 & 0.84 & 0.81 & 1.30 \\
$\begin{array}{l}\text { Sector Algodón } \\
\text { + sector Agr.p.C. } \\
\text { Sector Algodón } \\
\text { + Sect. Agr. p.Con }\end{array}$ & 9.5 & 1.94 & 2.03 & 1.56 & 1.51 & 1.53 & 1.16 & 0.90 & 1.61 \\
\hline
\end{tabular}

Fuente: Elaborado en base a datos de la Revista del Banco Central de Reserva de EI Salvador

\section{El algodón y el comerclo exterlor}

El algodón es considerado el segundo producto de exporlación de $\mathrm{El}$ Salvador, que conjuntamente al café y el azúcar generan más del $60 \%$ de las exporlaciones del país.

Específicamenle el algodón contribuye en promedio para el período 1978-86 con el $6.1 \%$ del valor tolal de las exportaciones, aunque a lo largo del periodo ha perdido importancia ya que en 1978 aportaba el $12.2 \%$ y para 1986 solamente aporlaba el $0.7 \%$, una reducción altamente significaliva que esta relacionado a la situación deprimida del mercado internacional del algodón.

El algodón propicia la generación de divisas necesaria a la imporlación de olro tipo de insumos y productos, al respecto se podría sefhalar que en 1978 habia contribuido con más de 210 millones de colones en divisas y para 1986 este aporle se habia reducido a 8.5 veces llegando a alcanzar los 24.6 millones de colones en divisas. Nuevamente una reducción significativa dado los requerimientos crecientes de insumos y prod- 
uctos para la economía y los aumentos de los precios de los bienes importados.

Oiro dato relevante es que para 1978 el tolal de divisas generadas por exportación de algodón permitió cubrir casi el $10 \%$ de las imporlaciones totales del pais, a través del período esta relación se ha ido reduciendo significativamente, de tal manera que para 1986 las divisas generadas por el algodón solo cubren el $0.6 \%$ de las imporlaciones tolales del pais.

Cuadro No. 29

Particlpaclón de las exportaclones del algodón en el total de exportaclones de EI Salvador.1978-1986

\begin{tabular}{l|c|c|c|c|c|c|c|c|c|c}
\hline $\begin{array}{l}\text { Ano } \\
\text { Indicador }\end{array}$ & 1978 & 1979 & 1980 & 1981 & 1982 & 1983 & 1985 & 1985 & 1986 & $\begin{array}{l}\text { Promedio } \\
\text { periodo }\end{array}$ \\
\hline $\begin{array}{l}\text { Exporaciones Alg. } \\
\text { Expon. Total }\end{array}$ & 12.2 & 7.6 & 8.1 & 6.9 & 6.6 & 7.3 & 1.4 & 4.5 & 0.7 & 6.1 \\
\hline
\end{tabular}

Fuente: Elaborado en base a datos de la Revista del Banco Central de Reserva de EI Salvador.

\section{La actlvidad algodonera y la ocupaclón de la mano de obra}

La actividad algodonera genera ocupación tanto en la fase agricola, agroindustrial y de comercialización. Se considera que en el conjunto puede generar empleo a 150.000 personas, posibilitando a su vez ingresos al igual número de familias.

En la fase agricola del algodón, que incluye siembra crecimiento y cosecha se requiere un promedio de 82 dias hombre por manzana, dado que el ciclo es de 257 dias se puede determinar el nivel de ocupación que genera este cultivo en cada afio agricola.

El cuadro No. 30 muestra que los requerimientos de mano de obra en el cultivo del algodón, han disminuido a una tasa promedio anual de - $17.9 \%$ durante el período de 1978 a 1987, disminución que es compatible con la lasa de decrecimiento de la superticie cullivada de este producto.

La reducción del área cultivada del algodón ha generado por lo menos un $86 \%$ de contracción en la cantidad de personas que se ocupaban entre la cosecha 1978/79 a la cosecha 1986/87. Impaclo serio en lérminos de ingresos familiares y capacidad de demanda de una proporción importante de población agricola.

Los electos de la disminución del área cultivada del algodón no solamente se mide en términos de producción sino lambién en la generación de ingresos vía empleo. Es de hacer notar que el carácter estacional del 
Cuadro No. 30

Ocupaclón generada por el cultivo del algodón tase agricola. 1978-1987

\begin{tabular}{|l|c|c|c|}
\hline Cosecha & $\begin{array}{c}\text { Dias/hombre } \\
\text { necesarios }\end{array}$ & $\begin{array}{c}\text { Tasa de } \\
\text { Variaciones }\end{array}$ & $\begin{array}{c}\text { Número de } \\
\text { personas }\end{array}$ \\
\hline $1978 / 79$ & 12.326 .978 & 3.5 & 47.965 \\
$1979 / 80$ & 10.628 .020 & -13.7 & 41.355 \\
$1980 / 81$ & 6.811 .330 & -36.1 & 26.504 \\
$1981 / 82$ & 6.785 .500 & -0.3 & 26.403 \\
$1982 / 83$ & 5.732 .374 & -15.5 & 22.305 \\
$1983 / 84$ & 4.462 .686 & -22.1 & 17.365 \\
$1984 / 85$ & 4.384 .786 & -1.7 & 17.062 \\
$1985 / 86$ & 3.274 .342 & -25.3 & 12.741 \\
$1986 / 87$ & 1.611 .300 & -50.7 & 6.270 \\
\hline
\end{tabular}

1. Se establece un promedio de 82 dlas/hombre por manzana sólo en la fase asgrlcola, sobre un año laborable de 257 dlas, por no ser un empleo totalmente permanente.

Fuenle: Elaborado en base a dalos de las Memorias de la COPAL.

Cuadro No. 31

Ocupación e Ingresos generados por el algodón en fases agrícolas, Industrlal y comercial

\begin{tabular}{|l|c|c|}
\hline Afios & $\begin{array}{c}\text { Personal } \\
\text { ocupado }\end{array}$ & $\begin{array}{c}\text { Dinero pagado } \\
\text { millones de }\end{array}$ \\
\hline $1977 / 78$ & 145.245 & 217.8 \\
$1978 / 79$ & 159.329 & 225.4 \\
$1979 / 80$ & 129.610 & 194.4 \\
$1980 / 81$ & 101.070 & 151.0 \\
$1981 / 82$ & 82.315 & 123.4 \\
$1982 / 83$ & 70.800 & 106.2 \\
\hline
\end{tabular}

Fuente:

cullivo proporciona ocupación en determinadas épocas a un contingente de población migranle, que se desplaza de distintas regiones del pais a las zonas algodoneras especialmente en la época de cosecha.

El cuadro No. 31 muestra la generación de empleo por el algodón en el conjunto de sus tases y los ingresos que genera en relación a los pagos hechos a esta población ocupada. Como se aprecia la ocupación asi como los ingresos (dinero pagado) decrece en los anos debido a la conlracción de la actividad algodonera. 
Cuadro No. 32

Participación de la ocupación de mano de obra del algodón en el total de la oferta de mano de obra agricola

\begin{tabular}{|l|c|c|c|}
\hline Anos & $\begin{array}{c}\text { Oferta M. O } \\
\text { dias-hombre }\end{array}$ & $\begin{array}{c}\text { Algodón } \\
\text { dias-hombre }\end{array}$ & $\begin{array}{c}\text { Participación } \\
\text { Algodón O.M.O. }\end{array}$ \\
\hline 1978 & 164.859 .075 & 12.326 .978 & $7.5 \%$ \\
1979 & 168.938 .950 & 10.628 .020 & $6.2 \%$ \\
1980 & 137.768 .051 & 6.811 .330 & $4.9 \%$ \\
1981 & 142.274 .686 & 6.785 .500 & $4.7 \%$ \\
1982 & 146.786 .064 & 5.732 .374 & $3.8 \%$ \\
\hline
\end{tabular}

Fuente: Elaborado en base a datos del Diagnóstico del Sistema Agropecuario 1978/83 OSPA. Ministerio de Agricultura y Ganaderia y cuadro No. 3.

Por úllimo el algodón conlribuye a generar solo en su fase agrícola el $5.4 \%$ promedio anuat de la ocupación del sector agropecuario; dado que la actividad a sufrido una contracción en los af́os ' 80 , su participación en la generación de empleo agricola se ha reducido hasla llegar a una tasa de $3.8 \%$ en 1982.

La aclividad algodonera requiere o genera un nivel de ocupación en el sector agropecuario importante, por lo que es necesario buscar alternativas para resolver los problemas o las causas que propician su aciual descenso en el área cultivada.

\section{Participación del sector en el empleo de capltal}

Se hace muy difícil cuantificar temporalmente la situación de parlicipación del capital empleado en el sector en relación al capital de loda la economia.

Duranle el período de 1978 a 1987 en la actividad algodonera en su fase agrícola, como de procesamiento y comercialización se han utilizado un conjunto de bienes de capital, al respecto no existen estadísticas censales recientes que nos permitan medir la situación actual.

El conflicto bélico ha incidido en la destrucción y deterioro de este tipo de bienes, los problemas de la producción algodonera han provocado ventas de mucho de este capilal (maquinaria, equipo, elc.). Por lo que se hace difícil determinar la importancia del sector en el empleo de capital.

A tin de tener alguna idea al repecto de esta relación ulilizaremos la matriz insumo-producto del Banco Central de Reserva que en base a dalos de 1978 muestra la estruclura de la economía salvadoreña. 
Bajo la malriz insumo producto a precios de adquisición de 1978 enconlramos que:

- El consumo de capital fijo lolal es 3.797 .721 miles de colones.

- El consumo de capital fijo del sector algodonero es de 6.490 miles de colones.

La relación de ambas variables da $0.17 \%$ esto quiere decir que el seclor algodonero participa en el empleo de capital de la economía con una minima proporción la cual es menor al $1 \%$.

El año 1978 es relativamente normal, represenla para la actividad algodonera un allo nivel de producción lograda durante la década de los 70 y de superlicie cultivada muy importante. Por lo tanto podriamos esperar que debido a las circunstancias y problemas que se presentaron durante los ańos ochenta esta pudo haberse deteriorado.

Es de considerar que la tecniticación en la fase de cosecha del algodón esla prohibida debido a las implicaciones que tendria en el empleo de mano de obra, este es uno de los factores que hace reducido su aporte al empleo de capital.

Es de considerar que la tecnificación en la fase de cosecha del algodón esla prohibida debido a las implicaciones que tendría en el empleo de mano de obra, este es uno de los lactores que hace reducido su aporte al empleo de capital.

En general la participación del sector algodonero en el empleo de capilal lotal de la economía es muy pequeńo, por lo lanto el impacto contractivo de la aclividad algodnera ha afectado más en términos de deterioro, perdida, deslrucción de bienes de capilal del sector algodonero que del conjunto de la economía.

\section{Algunas relfexiones en torno a las perspectivas del algodón en El Salvador}

Como se ha evidenciado la crisis algodonera es la manifeslación de un conjunto de laclores que estan inlimamente relacionados, esto significa que para entrentar esta grave situción es necesario actuar integralmenle a lin de erradicar o minimizar las causas propiciadoras y propagadoras de la aclual crisis algodonera.

Es decir que existen factores que a su vez tienen que ver con la crisis global que enirenta la economía salvadorefia, lo cual repercute negativamente sobre la actividad algodonera, en este sentido los desequilibrios económicos como la inflación, el déficit fiscal y el déficit externo reperculen negalivamenle sobre toda la actividad económica y concretamente sobre el cultivo del algodón ya sea por la vía de incremento de 
los costos de producción, por las dificultades de importación y sus implicaciones en sus costos, como por los precios poco remunerativos al productor.

Otros faclores que estan a la base de la eslructura productiva del algodón también han actuado negativamente, especialmenle sobre los pequeños productores que se han visto en condiciones adversas para enfrentar la gravedad de la crisis económica, nos referimos al impacto que los costos de producción tienen sobre las unidades produclivas pequefias que no pueden aprovechar los beneficios de escala en esta actividad.

Si bien los factores que impuisaron la crisis económica de los años ' 80 estaban ya presentes en la década de los '70, su incidencia se ve profundizada por lactores coyunturales que agravan y propagan más los efectos de la crisis global.

La guerra, la caida en los precios del algodón en el mercado internacional, la reducción de nuestros principales mercados de exporlación, asi como los cambios en la estructura de propiedad y organización de la producción por la relorma agraria, incidiéron como elementos desestimuladores de la actividad algodonera.

Olro aspecto a considerar son las políticas impulsadas por el gobierno, durante eslos af̂os, para Iratar de resolver la crisis, las cuales no lograron crear el clima adecuado para mayores inversiones en el cullivo del algodón, si bien muchas de ellas eran favorables al produclor (créditos, precios de garantia, subsidios, etc) estos adolecian de una visión parcial para resolver la crisis algodonera.

Ciertamente en la aclualidad nos enfrentamos al dilema, si el cullivo del algodón es lodavia una actividad necesaria a impulsar o será adecuado buscar alternativas de producción que sustituyan este cullivo. El problema es de tal complejidad que si deseamos manlener el cullivo debemos desarrollar una política integral que considere tanto la implemenlación de políticas agrícolas que estimulen la producción (crédilos blandos, refinanciamientos, precios remunerativos al produclor, asistencia técnica que entrente los problemas del abandono de las práclicas agroecológicas en este cultivo, precios bajos de insumos, elc). Pero al mismo liempo significa incidir sobre faclores como la guerra, el incremento de la produclividad agrícola, los precios deprimidos en el mercado internacional, promover la eficiencia y productividad en las unidades del seclor reformado elc.

Obviamenle la solución al conflicto armado es un aspecto que no esla bajo control de los productores, pero la solución de este problema (a través de medios políticos y no militares) y el papel que los produclores 
pueden jugar para su finalización no se puede desestimar. Más complejo aún es el problema de los precios internacionales del algodón sobre el cual no hay control, pero se podrla actuar sobre la busqueda de nuevos mercados para la fibra de algodón en mercados no tradicionales.

Por otra parte habra que pensar que el impacto negativo que tiene la caida de la producción algodonera sobre el empleo, la generación de divisas; y sobre la industria lextil, de hilados, aceites, la ganaderia y otras aclividades económicas (las cuales a su vez han sufrido las consecuencias de la crisis global y el conflicto armado) debe lievarnos a considerar medidas que reactiven estas aclividades económicas para que impulsen nuevamenle la producción de algodón y sus derivados.

Por último para evaluar la posibilidad de sustituir este cullivo debe considerarse aquellas alternalivas de producción agricola que generen un nivel de empleo y de divisas importante para la economla salvadorefia, a su vez debe lomarse en cuenta otros benelicios posibles de olros cullivos y los mecanismos que sustiluyan los requerimienlos de Insumos para las actividades económicas (industriales, agricolas, artesanales) que eslan articuladas a los requerimientos de insumos del algodón.

Las soluciones no son láciles, pero habra que actua $r$ pronto si no se desea que los electos negativos de la crisis algodonera se acentuen en el sector agrícola y en los olros sectores vinculados a ella.

NOTAS

- 1. Banco Interamericano de Desarrollo (BID). El Salvador Informe Socio Económico, 1986. pág. 55.

4 2. Ministerio de Agricultura y Ganaderla. Dirección General de Economla Agropecuaria. Evaluación del Cultivo del Algodón Cosecha 1982-83. El Salvador, 1984, pág. 11.

3. Ibid. pág. 11

4. Ibid. pág. 58

5. Op. cit Banco Interamericano de Desarrollo, pág. 55.

6. Proceso Inlormativo Sernanal. Centro Unviersitario de Documentación e Información. UCA. El Salvador No. 168, 1984, pág. 5.

1 7. Ministerio de Planilicación y Coordinación del Desarrollo Económico y Social (MIPLAN). Programa de Producción: El algodón, industria textil y del vestuario. El Selvador. 1986, pág. 30.

B. Ibid. pág. 32

9. Ibid. pág. 33

10. Landman, Jerry; Torrico, Isaac y Bunce, T. Dwight. Mercados financieros rurales de EI Salvador (Movilización de ahorros y crédito agropecuario) Preparado para USAID/. El Salvador 1986, pág. 19

11. Ibid. pág. 19 y 20.

12. En base a dalos proporcionados por diversas instituciones, tomado de Osegueda, Xenia y otros. "La incidencia de la guerra sobre la estructura económica y social de EI Salvador. 1979-1984. Tesis de Economla. UCA. 1986.

13. Op. cit. MAG. Evaluación del Cultivo del Algodón... pág. 24. 
14. Cooperativa Algodonera Salvadoreña (COPAL). Memoria Ejercicio XLVI Cosecha 1985/86, pág. 10.

15. Estadlsticas Agropecuarias. Dirección General de Economla Agropecuaria. Situación del Mercado de Productos Agropecuarios. 1985.

16. Ibid.

17. Op. Cit. COPAL Memoria Cosecha 1985/86. pág. 10.

18. Ibid. pág. 12.

19. En base a dalos de la "clasificación de las exportaciones e importaciones con base a la Nomenclalura Arancelaria Unilorme NAUCA:. Banco Central de Reserva de EI Salvador. 1986.

20. COPAL. Memoria ejercicio XLVII. Cosecha 1986/87. pág. 9.

21. Op. cit. Evaluación del Cultivo del Algodón... pág. 39.

22. Ibid. pág. 39.

23. Ibid. pág. 35

24. Ibid. pág. 31.

25. Ibid. pág. 59.

26. Ibid. pág. 59. 